\title{
Growth of metal halide perovskite materials
}

\author{
Shaoli Wang ${ }^{1,2}$, Fan Yang ${ }^{2,3}$, Jiangrui Zhu' ${ }^{2}$, Qinxuan $\mathrm{Cao}^{2,4}$, Yangguang Zhong ${ }^{2}$, Aocheng Wang ${ }^{2,3}$, \\ Wenna $\mathrm{Du}^{2}$ and Xinfeng Liu ${ }^{2,5^{*}}$
}

\begin{abstract}
Perovskite materials, especially metal halide perovskites, exhibit excellent properties, such as large optical coefficients, high carrier mobilities, long carrier lifetimes, tunable resistivities, large $X$-ray attenuation coefficients, and simple processing techniques. In recent decades, perovskites have attracted significant attention in the photoelectric field due to their versatile utility in solar cells, light-emitting diodes, photodetectors, $\mathrm{X} / \mathrm{\gamma}$-ray detectors, and lasing. However, the wide applicability of perovskites highly depends on the quality of perovskite crystals and films. Thus far, several perovskite growth technologies and methods have emerged. Therefore, this review classified and summarized the main methods that have been employed to achieve perovskite growth in recent years, including the solution temperaturelowering (STL) method, inverse temperature crystallization (ITC), anti-solvent vapor-assisted crystallization (AVC), spin coating, and chemical vapor deposition (CVD). Through analysis and summary, it has been determined that the STL, ITC, and AVC methods are mainly used to grow high-quality perovskite single crystals. While the spin-coating method has a significant advantage in the preparation of perovskite films, the CVD method is propitious in the fabrication of a variety of morphologies of micro/nano perovskite materials. We hope that this review can be a comprehensive reference for scientific researchers to prepare perovskite-related materials.
\end{abstract}

Keywords: growth methods, perovskite, solution growth, spincoating, CVD

\section{INTRODUCTION}

Perovskites, named after the Russian mineralogist, Perovski LA, initially referred to a calcium titanium oxide mineral composed of calcium titanate $\left(\mathrm{CaTiO}_{3}\right)$ [1]. Such terminology has since been extended to the kind of compounds that have a similar crystal structure as that of $\mathrm{CaTiO}_{3}$. In 1958, Møller [2-4] first reported that CsPbX ( $\mathrm{X}=\mathrm{Cl}, \mathrm{Br}, \mathrm{I})$ compounds comprise the perovskite structure. Twenty years later, Weber $[5,6]$ reported organicinorganic hybrid metal halide perovskites by replacing cesium with methyl ammonium (MA) cations. One of the most important goals in materials science is the synthesis of new compounds, as well as the exploration of applying all known compounds [4]. Since Miyasaka and his colleagues [7] first used metal halide perovskite as a visible photosensitizer of photoelectron chemical cells in 2009, the research on the preparation and application of perovskite materials has been on a daily increase. With the development of research, it has been found that metal halide perovskites have many excellent properties, such as large optical coefficients [8,9], high carrier mobilities [1012], long carrier lifetimes and diffusion lengths [13-15], as well as tunable resistivities [16], large X-ray attenuation coefficients, high fluorescence yields [16], wavelength tunability [17], and a simple processing technique [18,19]. Owing to these excellent properties, metal halide perovskite materials have become promising candidates for solar cells [20-28], lasers [29-33], luminescent devices [34-43], photodetectors [44-56], X-ray and $\gamma$-ray detectors [57], and so on, as shown in Fig. 1.

While the application of perovskite materials, in addition to the device structure, is impactful [58-60], two important factors need to be addressed: (i) the improvement in the material quality [61-63]; (ii) the development of different growth techniques [64-77]. The growth

\footnotetext{
${ }^{1}$ Experiment Center of Forestry in North China, Chinese Academy of Forestry, Beijing 102300, China

2 CAS Key Laboratory of Standardization and Measurement for Nanotechnology, CAS Center for Excellence in Nanoscience, National Center for Nanoscience and Technology, Beijing 100190, China

${ }^{3}$ Department of Chemistry, School of Science, Tianjin University, Tianjin 300072, China

${ }^{4}$ School of Materials Science and Engineering, Zhejiang University, Hangzhou 310027, China

${ }^{5}$ University of Chinese Academy of Sciences, Beijing 100049, China

*Corresponding author (email: liuxf@nanoctr.cn)
} 


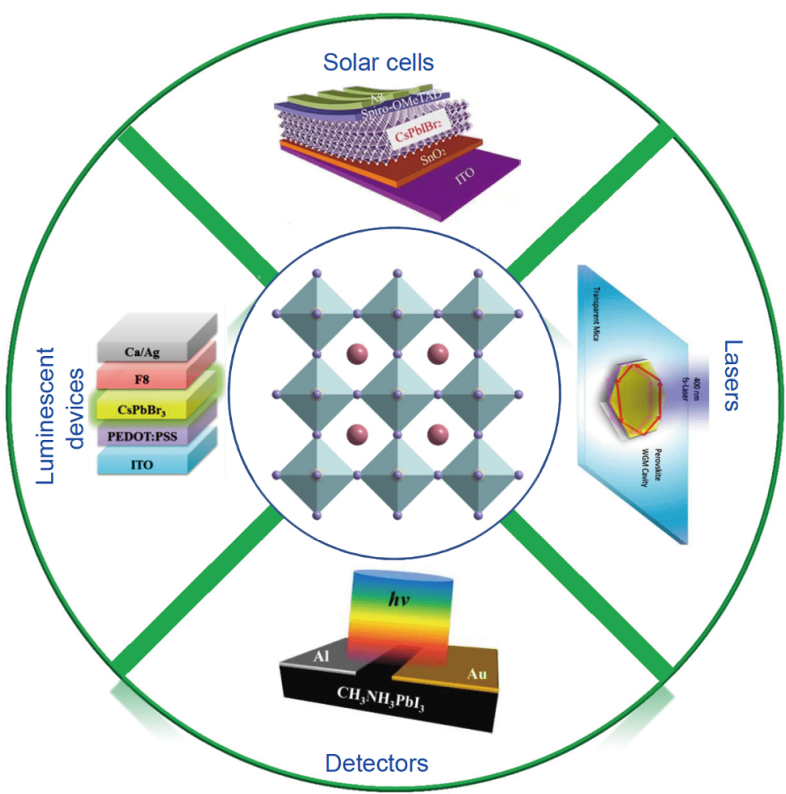

Figure 1 Main applications of metal halide perovskite materials. Reprinted with permission of the picture on the bottom from Ref. [50], Copyright 2016, the Royal Society of Chemistry; Reprinted with permission of the picture on the right from Ref. [31], Copyright 2014, the American Chemical Society; Reprinted with permission of the picture on the top from Ref. [28], Copyright 2019, the Royal Society of Chemistry; Reprinted with permission of the picture on the left from Ref. [35], Copyright 2015, the American Chemical Society.

processes have strong impacts on the material quality [78]. According to the different growth processes, the existing perovskite growth methods can be basically classified into the conventional solution growth method $[64,68,79,80]$, and the "new solution method"-spincoating $[28,69,81,82]$ and chemical vapor deposition (CVD) [74,76,78,83-85]. The conventional solution growth approach mainly included the solution temperature-lowering (STL), inverse temperature crystallization (ITC), and the anti-solvent vapor-assisted crystallization (AVC) methods.

The conventional solution growth method is mainly used for the growth of perovskite single crystals, especially for the growth of bulk crystals. Owing to the fewer grain boundaries and the corresponding extremely low trap densities in the perovskite crystal, the perovskite crystals are more promising for realizing high-performance optoelectronic devices $[17,86,87]$. To prepare high-quality bulk perovskite single crystals, researchers have conducted several explorations and extensive research on the growth methods of perovskite single crystals. According to previous research, it has been discovered that the processes during the conventional solution growth methods of perovskite single crystals, such as the STL $[1,79,88-90]$, ITC [91], and AVC methods $[1,79,88-90]$, have significant influence on the quality of perovskite single crystals.

The "new solution method", i.e., the spin-coating, is one of the cheapest film production methods, which is widely used in solution-processed perovskite solar cells. Owing to the strong ionic interaction between metal ions and halogen anions, the evaporation and convective selfassembly processes in spinning immediately induced the formation of well-crystallized perovskite materials [91]. Although the spreading diffusion flow, which caused centrifugal force, was applied to the slowly evaporating solvent [91], the simple spin-coating could not produce a uniform perovskite layer on a large area [92]. Thus, a variety of methods have been explored to optimize the fabrication procedure, including one-step [28], two-step [93] and multi-step spin coating [71]. For the production of uniform perovskite films with large areas, the CVD method has been widely adopted in several studies, such as low vacuum single step processing [94], sequential deposition processing [95-100], hybrid CVD (HCVD) [78,99], and the hybrid physical-CVD (HPCVD) method [96], as well as growth under atmospheric conditions $[101,102]$.

Herein, we classified and summarized the main methods that have been adopted for achieving perovskite growth in recent years, including the STL, ITC, AVC, spin coating, and CVD methods. Perovskites with different morphologies, such as bulk crystal, thin film, micro/nano platelet, nanowire, and micro/nano sphere, can be grown by different growth methods under different conditions. We hope, herein, that this review can provide a reference for scientific researchers in the selection of perovskite growth methods in the future.

\section{GROWTH METHODS OF METAL HALIDE PEROVSKITES}

The main growth methods of metal halide perovskites include the conventional solution, spin-coating, and CVD methods. Because of the versatility, simplicity, and low cost of the solution method, the conventional solution method occupies a prominent place in the growth of metal halide perovskites. Meanwhile, it is easier to grow high-quality single crystals, herein, compared with other methods. The spin-coating method is mainly used to fabricate perovskite thin films, which are mainly used to prepare solar cells. Furthermore, the spin-coating method is one of the least expensive film-forming methods. The CVD method is one of the numerous demonstrated ways 
for the vapor deposition of perovskites. With the development of the CVD method, high-quality perovskite materials with different morphologies can be grown, such as platelets, films, micro-, and nanowires.

\section{Solution method}

\section{STL growth method}

The improved original Weber's method, which formed the solution temperature, has become one of the classical methods for the growth of metal halide perovskites. The driving force of the crystal growth is the solution supersaturation, which is achieved by gradually lowering the solution temperature. Therefore, the solute solubility of perovskite crystals grown by the STL method needs to decrease with the lowering of the solution temperature. In the first stage of STL method, the saturated solution is first prepared at a relatively high temperature, and then the solution is gradually cooled to a certain temperature in a certain time (approximately $24 \mathrm{~h}$ ) for the precipitation of small seed crystals. In the second stage, the STL method can be divided into the bottom-seeded solution growth (BSSG) and the top-seeded solution growth (TSSG) methods, depending on the different fixed positions of the seed crystals, as shown in Fig. 2a, b. Summarily, the STL method initially synthesizes millimetersized crystals, and then, grows large-sized bulk single crystals by seed crystals.

Here, we introduce the research progress of the growth of metal halide perovskites by the BSSG method that has been adopted in recent years. In 1995, Mitzi and his coworkers [107] first prepared the cubic perovskite $\mathrm{CH}_{3} \mathrm{NH}_{3} \mathrm{SnI}_{3}\left(\mathrm{MASnI}_{3}\right)$ by precipitation from a hydriodic acid solution by the BSSG method. Initially, they gently heated the $\mathrm{CH}_{3} \mathrm{NH}_{2} \cdot \mathrm{HI}$ and $\mathrm{SnI}_{2}$ solutions in a water/ ethylene glycol bath to $90^{\circ} \mathrm{C}$ and then mixed the solutions together. After mixing the warm solutions, the resulting yellow solution was cooled to room temperature. Finally, the black-green precipitate formed, which was then filtered under flowing $\mathrm{N}_{2}$ and dried under flowing $\mathrm{Ar}$ at $100^{\circ} \mathrm{C}$ for $5 \mathrm{~h}$. In 2014, Tao's group [64] obtained largesized $\mathrm{MAPbI}_{3}$ bulk single crystals by the BSSG method. The seeded crystal was fixed to the middle of a designed tray in the growth chamber. The tray fixing the seed crystal was rotated by an electric motor. Then, the saturated solution was slowly cooled from 65 to $40^{\circ} \mathrm{C}$. After approximately one month, the single crystal $\mathrm{MAPbI}_{3}$ with the dimension of $10 \mathrm{~mm} \times 10 \mathrm{~mm} \times 8 \mathrm{~mm}$ was successfully obtained in the bottom of the flask, as shown in Fig. 2e. It should be noted that in the STL method, the temperature of the precursor solution needs to maintain uniformity during the crystal growth process. To realize the temperature uniformity of the precursor solution in the growth process, the temperature of the solution can be controlled by utilizing a programmable temperature controller. In 2015, by decreasing the temperature of the growth solution from 100 to $57^{\circ} \mathrm{C}$, Yan's group [108] also harvested centimeter-sized $\mathrm{MAPbI}_{3}$ bulk single crystals via the BSSG method over the course of $15 \mathrm{~d}$. In the process of seed growth, they found that $\mathrm{MAPbI}_{3}$ could easily crystallize and some deposits appeared in the bottom of the flask, which coud easily adhere to the surface of the growing seed during the cooling process. The growth of large-bulk single crystal of $\mathrm{MAPbI}_{3}$ was evidently hindered by the numerous formed crystal nuclei. To eliminate the negative effect, they fixed and supported the seed crystal with platinum wire to separate the seed crystal from the bottom of the flask. Later, Chen et al. [22] and Huang's team [109] noticed that the addition of chloride ions could control the morphological evolution and crystallinity of polycrystalline perovskite absorbers, thus improving the performance of the device. Therefore, by using chlorine as the medium of solution growth, they obtained large $\mathrm{MAPbI}_{3}(\mathrm{Cl})$ single crystals of $20 \mathrm{~mm} \times 18 \mathrm{~mm} \times 6 \mathrm{~mm}$ in $5 \mathrm{~d}$ by the BSSG method. Regarding the chlorine promoters, not only was the growth rate evidently improved but also the crystal quality was higher, without compromising on the crystallinity, carrier mobility and carrier lifetime [65]. The growth cycle of the STL approach is effectively shortened from several weeks to several days by chlorine additive, which greatly reduced the cost of crystal preparation. Other kinds of perovskites, such as $\mathrm{MAPbBr}_{3}$ [110], $\mathrm{MAPbCl}_{3}$ [110], $\operatorname{MAPb}\left(\mathrm{Cl}_{x} \mathrm{I}_{1-x}\right)_{3}$ [111], $\mathrm{NH}\left(\mathrm{CH}_{3}\right)_{3} \mathrm{SnX}_{3}(\mathrm{X}=\mathrm{Cl}, \mathrm{Br})$ [112], $\mathrm{FAPbI}_{3}$ [113], and $\mathrm{FA}_{(1-x)} \mathrm{MA}_{x} \mathrm{PbI}_{3}$ [114], have also been successfully prepared by the BSSG method.

To eliminate the influence of many seed crystals in the bottom of the flask during crystal growth via the BSSG method, many researchers chose to grow single crystals by the TSSG method. In 2015, Huang's group [103] reported large-sized $\mathrm{CH}_{3} \mathrm{NH}_{3} \mathrm{PbI}_{3}\left(\mathrm{MAPbI}_{3}\right)$ polycrystalline (MPC) growth from a supersaturated $\mathrm{MAPbI}_{3}$ solution using the TSSG method with a temperature gradient, as shown in Fig. 2b. The $\mathrm{MAPbI}_{3}$ single crystals (MSCs) gradually become larger by the consumption of small MSCs at the bottom. The small temperature difference between the bottom and the top of the solution created a small convection that is sufficient to transport the material to the large MSCs. Eventually, the obtained MSCs have an average size of $3.3 \mathrm{~mm}$ and a largest size of 
a

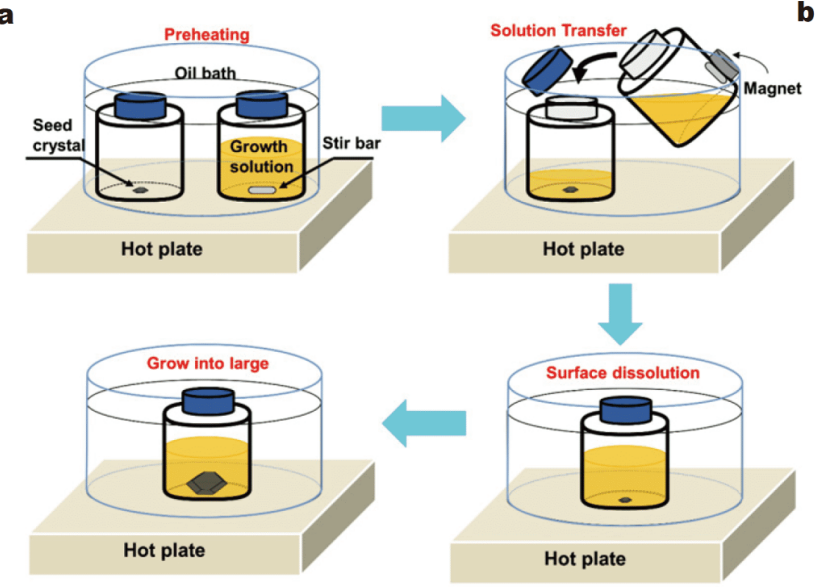

c

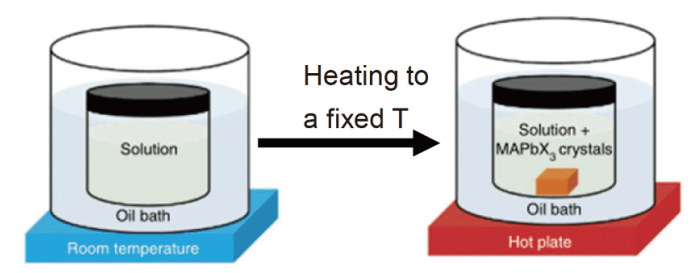

e

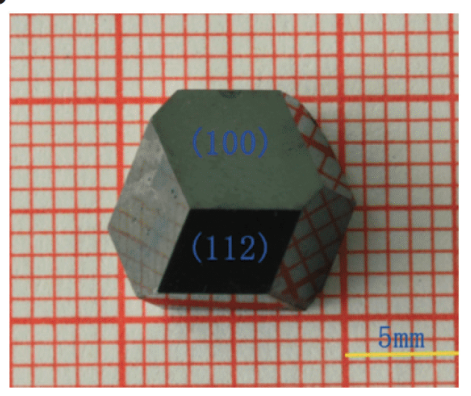

b

d
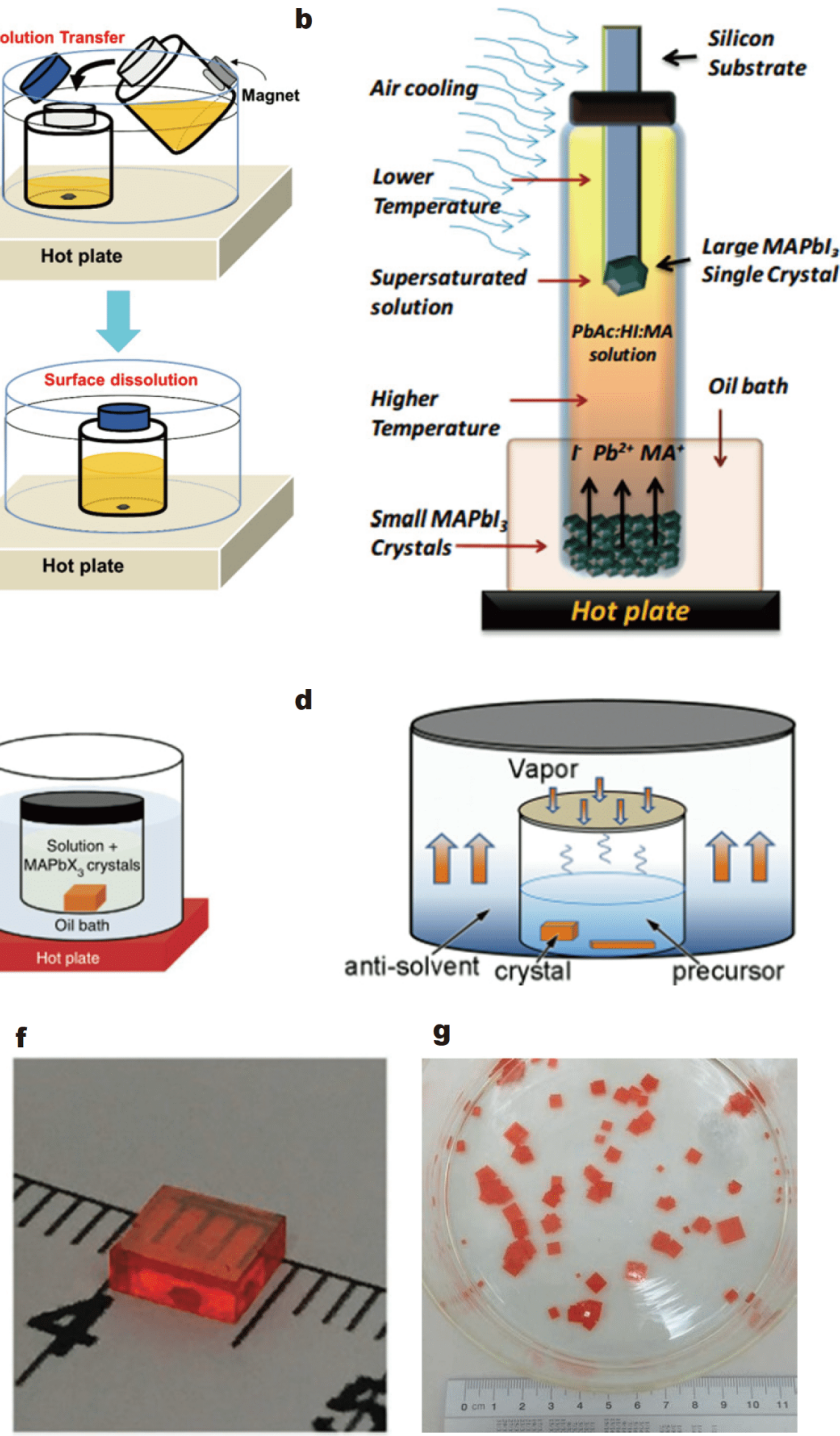

g

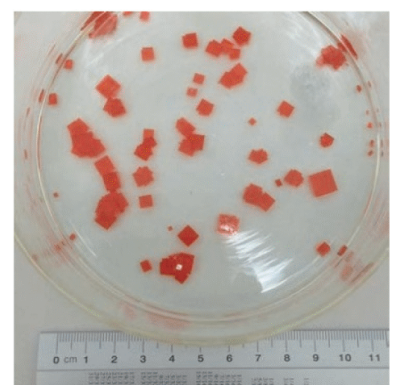

Figure 2 (a) Schematic of the BSSG method to grow large $\mathrm{MAPbI}_{3}(\mathrm{Cl})$ bulk single crystals. Reprinted with permission from Ref. [65]. Copyright 2016, the American Chemical Society. (b) Schematic illustration of the TSSG method. Reprinted with permission from Ref. [103]. Copyright 2015, the American Association for the Advancement of Science. (c) Schematic representation of the ITC apparatus in which the crystallization vial is immersed within a heating bath. Reprinted with permission from Ref. [91]. Copyright 2015, the Springer Nature. (d) Schematic of the AVC method. Reprinted with permission from Ref. [104]. Copyright 2017, the American Chemical Society. (e) $\mathrm{CH}_{3} \mathrm{NH}_{3} \mathrm{PbI}_{3}$ crystal by STL method. Reprinted with permission from Ref. [64]. Copyright 2014, the Royal Society of Chemistry. (f) FAPbBr ${ }_{3}$ crystal grown by ITC method. Reprinted with permission from Ref. [105]. Copyright 2015, the Royal Society of Chemistry. (g) Crystallization of $\mathrm{MAPbBr}_{3}$ by AVC method. Reprinted with permission from Ref. [106]. Copyright 2015, the American Association for the Advancement of Science.

$\sim 10 \mathrm{~mm}$. The crystals are stable in air and could maintain the metal-like shinning surface for at least 6 months. In 2016, Tao's group [115] first obtained both cubic $\mathrm{CH}_{3}$ $\mathrm{NH}_{3} \mathrm{SnI}_{3}\left(\mathrm{MASnI}_{3}\right)$ and $\mathrm{CH}\left(\mathrm{NH}_{2}\right)_{2} \mathrm{SnI}_{3}\left(\mathrm{FASnI}_{3}\right)$ single crystals under ambient atmosphere by the TSSG method, and the dimensions of single crystals reached $20 \mathrm{~mm} \times$ $16 \mathrm{~mm} \times 10 \mathrm{~mm}$ and $8 \mathrm{~mm} \times 6 \mathrm{~mm} \times 5 \mathrm{~mm}$, respectively.

Summarily, STL methods provide a simple, convenient and applicable technique for the growth of bulk-sized perovskite single crystals. However, it is really time-consuming, and usually needs $2-4$ weeks to harvest a single crystal of approximately $1 \mathrm{~cm}$.

\section{ITC growth method}

Generally, the solubility of the precursor solution increases with an increase in temperature. However, there is 
a relatively rare phenomenon that the solubility decreases with the temperature increase in some solutions. The inverse temperature-solubility behavior of $\mathrm{MAPbX}_{3}$ perovskites in certain solvents was first found by Bakr's group [91]. According to this abnormal phenomenon, they developed the ITC method to grow $\mathrm{MAPbX}_{3}$ single crystals (Fig. 2c), which is a rapid crystal growth approach. In the ITC method, crystals with controllable sizes and shapes can be formed in hot solution. Approximately $5-\mathrm{mm}$-length $\mathrm{MAPbI}_{3}$ single crystals were obtained only in $3 \mathrm{~h}$. The fastest growth rate of $\mathrm{MAPbBr}_{3}$ single crystals was revealed to be up to $38 \mathrm{~mm}^{3} \mathrm{~h}^{-1}$ at the third hour. The solvents and the growth temperatures were different under the condition of different halogens in the crystals. For example, the solvent of $\mathrm{PbBr}_{2}$ and $\mathrm{MABr}$ in the precursor solution was $\mathrm{N}, \mathrm{N}$-dimethylformamide (DMF), while the solvent of $\mathrm{PbI}_{2}$ and methylammonium iodide (MAI) was $\gamma$-butyrolactone (GBL). The bromide solution was usually prepared at room temperature $\left(25^{\circ} \mathrm{C}\right)$, and the iodide solution needed to be heated to $60^{\circ} \mathrm{C}$. The temperatures at which $\mathrm{Br}$ - and Ibased crystals begin to grow also differ.

In practical applications, especially commercial applications, large-sized single crystals are needed. Liu's group [14] obtained inch-sized $\mathrm{MAPbX}_{3}$ crystals with high crystallinity via the ITC method. They initially harvested the largest $\mathrm{CH}_{3} \mathrm{NH}_{3} \mathrm{PbI}_{3}$ crystal that had dimensions of $71 \mathrm{~mm} \times 54 \mathrm{~mm} \times 39 \mathrm{~mm}$, which exceeded half an inch. Liu's group not only grew a series of large single-halide perovskite crystals, including $\mathrm{CH}_{3} \mathrm{NH}_{3} \mathrm{PbCl}_{3}, \mathrm{CH}_{3} \mathrm{NH}_{3}$ $\mathrm{PbBr}_{3}$, and $\mathrm{CH}_{3} \mathrm{NH}_{3} \mathrm{PbI}_{3}$, but also grew large-scale dualhalide perovskite single crystals by the ITC method, which included $\mathrm{CH}_{3} \mathrm{NH}_{3} \mathrm{~Pb}\left(\mathrm{Cl}_{x} \mathrm{Br}_{1-x}\right)_{3}$ and $\mathrm{CH}_{3} \mathrm{NH}_{3} \mathrm{~Pb}$ $\left(\mathrm{Br}_{x} \mathrm{I}_{1-x}\right)_{3}$, with the maximum crystal length reaching $120 \mathrm{~mm}$ [117].

The large-crystal growth process mainly included two steps: (i) the seed crystal was obtained in a supersaturated solution. When the precursor was heated to a certain high temperature and kept for $12 \mathrm{~h}$, numerous small-sized seed crystals could be obtained from the supersaturated solution. (ii) High-quality seed crystals grew continuously in a fresh solution. By choosing one high-quality seed placed into the supersaturated precursor solution and kept for a certain period of time, the original seed grew to a larger crystal. To prepare larger crystals, the abovementioned steps need to be continuously repeated $[14,117]$.

In the ITC method, the key to growing a good single crystal is to choose the right solvent. After special investigation, Bakr's team $[79,105]$ found that a specific solvent is most suitable for a specific halide perovskite. For example, they found that GBL is generally suitable for I-based perovskites, whereas the more polar DMF is the suitable solvent for the Br-based ones to induce retrograde solubility. Furthermore, they found that dimethylsulfoxide (DMSO) works best for $\mathrm{MAPbCl}_{3}$. The retrograde behavior and ITC are not limited to the growth of $\mathrm{MAPbX}_{3}$ perovskites, but can be extended to the growth of $\mathrm{FAPbX}_{3}$ by solvent selection [79,105], as shown in Fig. 2f. When growing the $\mathrm{FAPbI}_{3}$ crystal by the ITC method, the solvent used was GBL, and the temperature needed to be heated to $115^{\circ} \mathrm{C}$. However, for the ITC method to grow $\mathrm{FAPbBr}_{3}$, the solvent used was 1:1 $(v / v)$ DMF:GBL, and the temperature at which the crystals began to grow was $55^{\circ} \mathrm{C}[79,113]$.

In addition to organic-inorganic hybrid halide perovskites, all inorganic halide perovskite single crystals can be grown by the ITC method. Using low-cost precursors, Kovalenko's team [116] prepared $\mathrm{Cs} \mathrm{PbBr}_{3}$ single crystals in ambient atmosphere by the ITC method. They found that $\mathrm{CsPbr}_{3}$ was best grown in DMSO. Therefore, they dissolved $\mathrm{CsBr}: \mathrm{PbBr}_{2}$ in a mixture of DMSO with cyclohexanol $(\mathrm{CyOH})$ and $\mathrm{DMF}$ to form the precursor solution, and heated it to $90^{\circ} \mathrm{C}$ in a vial, thereafter forming 13 nuclei. It was then heated to $110^{\circ} \mathrm{C}$, resulting in further growth without additional nucleation. In a few hours, a flat, orange, and optically transparent single crystal with a length of approximately $8 \mathrm{~mm}$ was collected. Using $\mathrm{MeCN}$ and $\mathrm{MeOH}$ as solvents, Hodes's team [67] also obtained $\mathrm{CsPbBr}_{3}$ single crystals by using a modified ITC method. To eliminate the appearance of undesirable precipitants (mostly the $\mathrm{Cs}_{4} \mathrm{PbBr}_{6}$ ), they used a two-step heating cycle. At first, they heated the solution to the required temperature for $4 \mathrm{~h}$, and then decreased it to room temperature by continuous stirring. They found that there were no other retrograde soluble compounds except for the orange $\mathrm{CsPbBr}_{3}$ crystal during the second heating cycle. The $\mathrm{Cs} \mathrm{PbBr}_{3}$ crystal evidently appeared only above approximately $120^{\circ} \mathrm{C}$ in the $\mathrm{MeCN}$-saturated solution, while the $\mathrm{CsPbBr}$ crystal were apparent at approximately $40^{\circ} \mathrm{C}$ in the $\mathrm{MeOH}$-saturated solution. It should be noted that only the bottom of the bottle can be heated to avoid crystal growth on the side of the bottle. Almost at the same time, Bakr's team [68] fabricated large and high-quality inorganic cesium lead halide single crystals using a similar ITC method. The production of $\mathrm{CsBr}$ and $\mathrm{PbBr}_{2}$ is easy to form different compositions, including $\mathrm{Cs}_{4} \mathrm{PbBr}_{6}, \mathrm{CsPb}_{2} \mathrm{Br}_{5}$, and $\mathrm{CsPbBr}_{3}$. They noted that the formation temperature of $\mathrm{CsPb}_{2} \mathrm{Br}_{5}$ was lower than that of $\mathrm{CsPbBr}_{3}$. Therefore, $\mathrm{CsBr}$ and $\mathrm{PbBr}_{2}$ were 
dissolved in DMSO according to the molar ratio of 1:2 to form the precursor solution, which was filtered and heated to $120^{\circ} \mathrm{C}$. Then, they harvested the isolated, millimeter-sized, rectangular, pure orange $\mathrm{CsPbBr}_{3}$ crystals. Choosing DMF as the solvent, they obtained a needlelike, yellow phase of $\mathrm{CsPbI}_{3}$ by a similar technique.

In the ITC method, the crystallization is induced by the solubility, which is inversely proportional to the temperature, in a specific organic solvent, and the whole crystal growth process is completed in a few hours. The ITC method is much faster than the STL method; therefore, the former is mainly used to rapidly grow larger-sized single crystals of metal halide perovskites.

\section{AVC growth method}

Based on the different solubilities of perovskite compounds in different solvents, the AVC crystal growth method was developed $[1,79,88-90]$. It was reported that $\mathrm{MAPbI}_{3}$ films were prepared by thermal evaporation from the precursor with $\mathrm{Cl}^{-}$-based metal salt. Then, they found that the carrier diffusion lengths of the films were two times longer than those of the best solution-treated material $[10,124]$. To obtain high-quality perovskite films, Tidhar's team [125] introduced the concept of antisolvent-assisted crystallization into the sample preparation for the first time in 2014. Inspired by those, Bakr's team [106] first obtained high-quality $\mathrm{MAPbX}_{3}$ with millimeter-scale via the AVC method, as shown in Fig. 2g. Fig. 2d shows the scheme of the AVC method. They dissolved MAX and $\mathrm{PbX}_{2}$ in DMF or $g$-butyrolactone (GBA) to prepare the precursor, and used dichloromethane (DCM) as an anti-solvent to prepare the $\mathrm{MAPbX}_{3}$ crystal. In another report, Yang's group [118] selected DMF as the precursor solvent and toluene as the anti-solvent to induce crystallization of $\mathrm{MAPbBr}_{3}$. At last, they obtained orange block-shaped single crystals by the AVC method. Using DMF/DCM as the solvent/antisolvent, Loi's group [119] grew a few millimeter-sized $\mathrm{MAPbBr}_{3}$ single crystals with a self-made simple device by the AVC method in several days. Similarly, Zhang's group [122] reported that $\mathrm{MAPbI}_{3}$ single crystals were grown by an improved AVC method in diethyl ether (DE) as the anti-solvent. Using acetonitrile and iodate/DE as precursors/anti-solvent, Grancini's group [123] obtained dark, highly reflective block $\mathrm{MAPbI}_{3}$ single crystals by the AVC method. Using DMF/DCM as the solvent/ anti-solvent, Liao's group [120] initially synthesized single-crystalline, square micro disks (MDs) of $\mathrm{MAPbBr}_{3}$ by a modified AVC method, which was named the "one-step solution self-assembly method". The four sides of the obtained $\mathrm{MAPbBr}_{3}$ constitute a built-in whispering-gallery mode microresonator, and the quality factor reached a value of approximately 430 . To understand the growth mechanism of $\mathrm{MAPbBr}_{3}$ crystals, Xu's group [121] synthesized the intermediate states of these crystals on filter paper by using the modified AVC method, which is similar with the "one-step solution self-assembly method" of Liao's group. Bakr's team [126] was concerned that macro-perovskite crystals could not grow on flat substrates, limiting their potential for optoelectronic integration. Thus, they synthesized large-area $\mathrm{MAPbBr}_{3}$ crystalline films using the AVC crystallization technique, which entailed large perovskite single crystals. The mobility and diffusion length of crystal films are similar to those of single crystals. The key operation involved was introducing a stirring force into the crystallization dish in the modified AVC method, which could be used to prepare two-dimensional integrated single-crystal perovskites.

Inorganic perovskite crystals can also be grown by the AVC method. Rakita's team [67] obtained $\mathrm{CsPbBr}_{3}$ single crystals by a modified AVC method. In this method, the precursor solution was formed by the $\mathrm{CsBr}$ and $\mathrm{PbBr}_{2}$ dissolved in $\mathrm{DMSO}$ at $50^{\circ} \mathrm{C}$ and $\mathrm{MeCN}$ or $\mathrm{MeOH}$ was selected as the anti-solvent. The key step of this method was to add a pre-saturation step, which could prevent undesired $\mathrm{Cs}_{4} \mathrm{PbBr}_{6}$ from settling along the side of the required $\mathrm{CsPbBr}$. After optimization, $\mathrm{Cs} \mathrm{PbBr}_{3}$ perovskite crystals with a millimeter scale and $100 \%$ yield can be grown without seed crystal. There are three different phases of cesium lead bromine, including $\mathrm{CsPbBr}_{3}$, $\mathrm{CsPb}_{2} \mathrm{Br}_{5}$, and $\mathrm{Cs}_{4} \mathrm{PbBr}_{6}$. Therefore, obtaining high-quality large-sized $\mathrm{Cs} \mathrm{PbBr}_{3}$ crystals by the AVC method remains a challenge. Zhang's group [104] has grown $\mathrm{CsPbBr}{ }_{3}$ crystals from a low temperature solution by the AVC method, where the largest $\mathrm{Cs} \mathrm{PbBr}_{3}$ crystals reached $42 \mathrm{~mm} \times 5 \mathrm{~mm} \times 3 \mathrm{~mm}$. After analyzing the phase diagram of cesium lead bromine, they got the optimized AVC method, in which the ratio of $\mathrm{PbBr}_{2}$ and $\mathrm{CsBr}$ was 1.5 in the precursor, while $50 \% \mathrm{MeOH}$ and $50 \%$ DMSO were selected as the anti-solvent. Under optimized conditions, Ding's team obtained orthorhombic $\mathrm{CsPBBr}_{3}$ single crystals using $\mathrm{DMSO} / \mathrm{MeOH}$ as solvent/anti-solvent by the AVC method. The growth temperature and the diffusion rate of anti-solvent methyl alcohol can affect the growth process of $\mathrm{CsPbBr}_{3}$ single crystals. By adjusting the temperature to $40^{\circ} \mathrm{C}$ and controlling the diffusion rate of methyl alcohol vapor in the growth solution (adjusting the number of pores), $\mathrm{CsPBr}_{3}$ single crystals with different shapes were successfully grown [127]. The anti- 
solvent plays an important role during the growth of inorganic perovskite single crystals by the AVC method. If $\mathrm{DMSO} / \mathrm{DE}$ is selected as a solvent and anti-solvent pair, $\mathrm{Cs}_{4} \mathrm{PbBr}_{6}$ crystallites can be obtained under similar conditions. Therefore, the researchers believed that the final crystallization products in the AVC method were determined by the miscibility of the solvent and the antisolvent. Thus, it is demonstrated that the high miscibility (such as $\mathrm{MeOH}$ in DMSO) initially produces $\mathrm{CsPbBr}_{3}$ and then $\mathrm{CsPb}_{2} \mathrm{Br}_{5}$; while low miscibility (such as $\mathrm{DE}$ in DMSO) directly produces $\mathrm{Cs}_{4} \mathrm{PbBr}_{6}[128]$.

Using the AVC method, perovskite thin film crystals or nanowire arrays can also be grown. Bakr's group [129] successfully prepared and characterized the hybrid perovskite monocrystalline films on substrates by using a modified AVC method that they termed cavitation-triggered asymmetrical crystallization (CTAC). This method overcomes the shortcomings of traditional single-crystal growth methods in its tendency to produce merely freestanding perovskite single crystals.

The CTAC strategy would promote heterogeneous nucleation by providing enough energy to overcome the nucleation barrier. Briefly, to obtain the perovskite films, a very short ultrasonic pulse $(\approx 1 \mathrm{~s})$ was introduced into the solution when the solution reached a low supersaturation with anti-solvent vapor diffusion, which is the key contribution of the CTAC method [129]. Pan's group [130] achieved the fabrication of large-area inorganic perovskite monocrystalline thin films by a space-limited AVC method. The schematic illustration of the inorganic perovskite monocrystalline thin films growth is shown in Fig. 3a. A stock solution $(50 \mu \mathrm{L})$ of equimolar $\mathrm{CsBr}$ and $\mathrm{PbBr}_{2}$ in DMSO was spread on a $2.5 \mathrm{~cm} \times 2.5 \mathrm{~cm}$ hydrophilic substrate. Then, another octadecyltrichlorosilane (OTS)-treated hydrophobic substrate was brought into contact with the DMSO solution, and the two clean flat substrates were clipped together. Pressure was applied uniformly on the two substrates. The bubbles in the solution were eliminated by a few seconds of vacuum pumping. Then, they were placed in a sealed glass beaker, which contained acetonitrile $\left(\mathrm{CH}_{3} \mathrm{CN}\right)$. The glass beaker can be put in a $40^{\circ} \mathrm{C}$ oven to boost the growth rate. Since $\mathrm{CH}_{3} \mathrm{CN}$ is a poor solvent for $\mathrm{CsPbr}_{3}$ and its dielectric constant is close to that of DMSO, a slow diffusion of $\mathrm{CH}_{3} \mathrm{CN}$ vapor into DMSO solution would induce the nucleation of $\mathrm{CsPbBr}_{3}$ (Fig. 3a-iii) rather than $\mathrm{CsBr}$-rich $\mathrm{Cs}_{4} \mathrm{PbBr}_{6}$ or $\mathrm{PbBr}_{2}$-rich $\mathrm{CsPb}_{2} \mathrm{Br}_{5}$, and the subsequent growth of $\mathrm{CsPbBr}_{3}$ monocrystalline films between two clipped substrates [130].

$\mathrm{CsPbBr}_{3}$ has excellent optoelectronic properties and shows great potential in laser applications. In particular, $\mathrm{CsPbBr}{ }_{3}$ nanowire arrays with controlled growth size and position are conducive to cost-effective and large-scale expansion to on-chip devices. Pan's group [131] successfully obtained a $\mathrm{CsPbr}_{3}$ microwire (MW) single crystal array with adjustable width, length, and position by using a polydimethylsiloxane (PDMS) templateconfined AVC method. Briefly, the equimolar $\mathrm{CsBr}$ and $\mathrm{PbBr}_{2}$ were dissolved in DMSO at $50^{\circ} \mathrm{C}$. After titration with $\mathrm{MeCN}$ until the orange precipitate disappeared, the precursor solution was formed. The PDMS template was brought into contact with the DMSO solution and the pressure was applied uniformly on the PDMS to drive the solution into the void space of the PDMS template. Then, the $\mathrm{SiO}_{2} / \mathrm{Si}$ substrates coated with the precursor solution were put into a crystallizing dish containing $\mathrm{CH}_{3} \mathrm{CN}$. The $\mathrm{CsPbBr}{ }_{3}$ MWs can crystallize with the diffusion of $\mathrm{CH}_{3}$ $\mathrm{CN}$ vapor into the precursor solution. With the extension of reaction time, the DMSO in the precursor solution gradually volatilized and the MWs gradually became
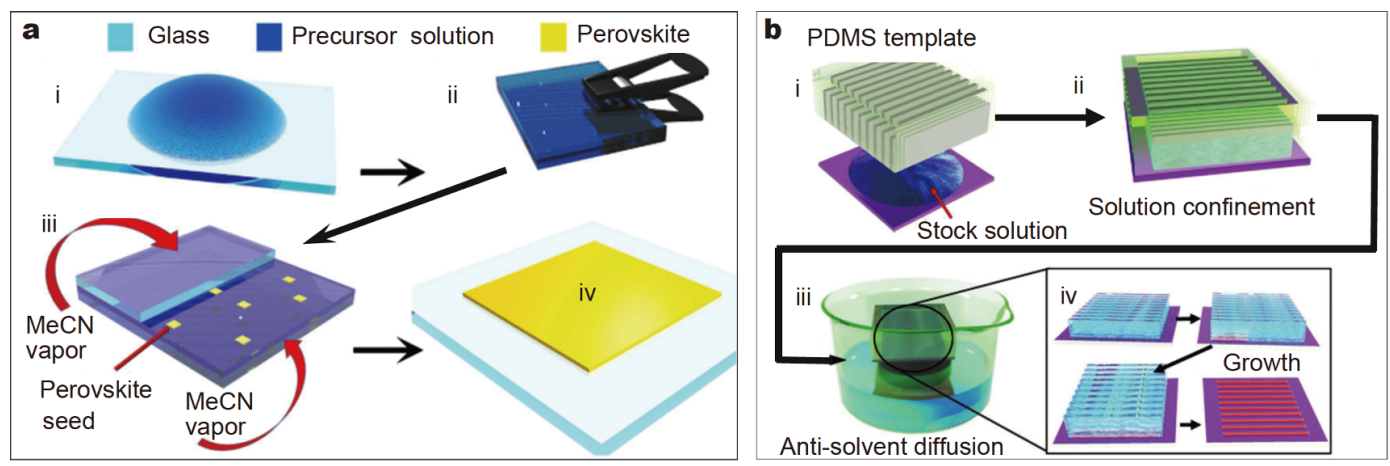

Figure 3 (a) Schematic diagram for growth of $\mathrm{CsPbBr}_{3}$ monocrystalline films. Reprinted with permission from Ref. [130]. Copyright 2018, Wiley. (b) Schematic diagram showing the entire preparation procedure of $\mathrm{Cs} \mathrm{PbBr}_{3} \mathrm{MW}$ arrays using the PDMS template-confined anti-solvent crystallization method. Reprinted with permission from Ref. [131]. Copyright 2019, Wiley. 
longer. After $12 \mathrm{~h}$, the entire reaction system was collected, washed with $\mathrm{CH}_{3} \mathrm{CN}$, thermally dried, and refilled with a new precursor solution (without peeling off the PDMS). After repeating the above-mentioned steps, the PDMS templates can be peeled off from the substrates. Finally, the MW arrays can be obtained after washing with $\mathrm{CH}_{3} \mathrm{CN}$ and drying with $\mathrm{N}_{2}$ stream. This method is relatively easy to prepare large-scale $\mathrm{Cs} \mathrm{PbBr}_{3} \mathrm{MW}$ arrays with controlled width, length, and position.

In the AVC method, DMF, DMSO, and GBL are commonly used as good solvents during the growth of metal halides, while chlorobenzene, chloroform, benzene, xylene, 2-propanol, toluene, DE, and acetonitrile are often used as anti-solvents. However, choosing the right solvent/anti-solvents is key to crystal growth. Therefore, it is essential to choose the appropriate solvent/anti-solvent, according to the specific reaction system. The AVC method has a relatively low dependence on temperature during crystal growth. Compared with the STL and ITC methods, it is generally difficult to obtain large-sized single crystals by the AVC method.

In the STL method, the crystal growth rate is slow because of the small daily temperature drop and the small supersaturation. However, due to the large volume of the solution and the long growth time, it is easy to grow large-scale and high-quality perovskite single crystals. In the ITC method, because the solution temperature rises to a certain level in a relatively short period of time, the supersaturation of the solution is large. Therefore, the ITC method can generally form perovskite single crystals with medium sizes in a relatively short period of time, as shown in Table 1. In the AVC method, with the diffusion of the anti-solvent in the solvent over a period of time, the solution will reach the critical value of supersaturation in an instant, and a large number of crystal nuclei will form and grow gradually. Therefore, perovskite single crystals grown by the AVC method are usually small in size and large in number.

\section{Spin-coating method}

The spin-coating method is also adopted in preparing perovskite materials. This method is a low-cost film production method and mainly used in solar cells of solution-processed perovskites. Summarily, the growth of perovskite crystals in spin-coating involves three processes: the solution reaches supersaturation, nucleation, and subsequent growth towards a large crystal [132-136]. Firstly, the solvent rapidly evaporates when the precursor solution is dropped on the substrate, then the concentration of the solute increases, and the precursor so- lution can quickly reach saturation $\left(\mathrm{C}_{\mathrm{s}}\right)$. At this point, however, nucleation cannot occur owing to the critical energy barrier. As the solvent continues to evaporate, when the solution reaches supersaturation $\left(\mathrm{C}_{\mathrm{ss}}\right)$ and the Gibbs free energy is above the energy barrier, the new crystal nuclei can form. Secondly, more crystal nuclei are formed and gradually grow with the continuous evaporation of the solvent. With the steady formation of crystal nuclei and the gradual growth of crystals, an increasing amount of solutes will be consumed. When the solution concentration is lower than $\mathrm{C}_{\mathrm{ss}}$, the nucleation process can stop, while for the solution concentration lower than the $\mathrm{C}_{\mathrm{s}}$, the new formed crystal can stop growing. Generally, GBL, DMSO, DMF and N-methyl-2pyrrolidone are selected as the solvents for lead halide and MAI. However, although the convection diffusion due to the centrifugal force during the spin-coating process facilitates the slow evaporation of the solvent, simple spin-coating cannot produce a uniformly thick perovskite layer over a large area [92]. The quality of perovskite films plays a key role in the photovoltaic performance of perovskites. Tight and well-crystallized perovskite films are a prerequisite for the preparation of high-efficiency solar cells [137].

\section{$N$-step methods spin-coating}

\section{(1) One-step method}

Due to the volatility and hygroscopic properties of organic cations, such as $\mathrm{CH}_{3} \mathrm{NH}_{3}^{+}\left(\mathrm{MA}^{+}\right)$and $\mathrm{CH}_{3}\left(\mathrm{NH}_{2}\right)^{2+}$ $\left(\mathrm{FA}^{+}\right)[93,129,138]$, hybrid perovskites have some instabilities, which become huge obstacles to their development. Therefore, the inorganic perovskite with $\mathrm{Cs}^{+}$and $\mathrm{Rb}^{+}$cations has attracted great interest in development. Yin's team [28] obtained a high-quality $\mathrm{CsPbIBr}_{2}$ film through a simple one-step spin-coating method with a preheating process. The process of preparing the $\mathrm{CsPbIBr}{ }_{2}$ perovskite thin film by the preheating-assisted spin-coating approach, is shown in Fig. 4a. Initially, the $\mathrm{SnO}_{2} /$ ITO substrates were placed on a hot plate for $10 \mathrm{~min}$. Then at room temperature, the $\mathrm{PbBr}_{2}$ and CsI were dissolved in DMSO to prepare the $\mathrm{Cs} \mathrm{PbIBr}_{2}$ precursor. The precursor solution was spin-coated on a preheated $\mathrm{SnO}_{2} /$ ITO substrate at $5000 \mathrm{rmin}^{-1}$ for $60 \mathrm{~s}$, and then, the perovskite film was obtained after a twostep annealing process. After the substrate was preheated, the residual heat on the substrate could accelerate the evaporation rate of the solvent, which played a key role in improving the quality of the film. After optimization, high coverage and high crystallinity helped to generate more light-induced carriers in $\mathrm{CsPbIBr}_{2}$ films and re- 
Table 1 Typical metal halide perovskite crystals grown by solution methods

\begin{tabular}{|c|c|c|c|c|c|c|c|c|}
\hline $\begin{array}{l}\text { Growth } \\
\text { method }\end{array}$ & Crystal & $\begin{array}{l}\text { Ratio of raw } \\
\text { material }\end{array}$ & $\begin{array}{c}\text { Solvent/ } \\
\text { anti-solvent }\end{array}$ & $\begin{array}{l}\text { Growth tem- } \\
\text { perature } T\left({ }^{\circ} \mathrm{C}\right)\end{array}$ & Growth time & Crystal color & Crystal size & Ref. \\
\hline \multirow{5}{*}{ BSSG } & $\mathrm{MASnI}_{3}$ & $\begin{array}{c}\mathrm{CH}_{3} \mathrm{NH}_{2} \cdot \mathrm{HI} / \\
\mathrm{SnI}_{2}=1: 1\end{array}$ & $\mathrm{HI}$ & $90-\mathrm{RT}^{\mathrm{a}}$ & - & $\begin{array}{l}\text { Black- } \\
\text { green }\end{array}$ & - & [107] \\
\hline & $\mathrm{NH}\left(\mathrm{CH}_{3}\right)_{3} \mathrm{SnCl}_{3}$ & $\begin{array}{c}\mathrm{SnCl}_{2} \cdot 2 \mathrm{H}_{2} \mathrm{O} / \\
\mathrm{NH}\left(\mathrm{CH}_{3}\right)_{3} \mathrm{Cl}=1: 1\end{array}$ & $\mathrm{HCl}+\mathrm{H}_{3} \mathrm{PO}_{2}$ & 54-RT & One month & Colorless & $13 \underset{\times 6 \mathrm{~mm}}{\mathrm{~mm} \times 8 \mathrm{~mm}}$ & \multirow{2}{*}[112]{} \\
\hline & $\mathrm{NH}\left(\mathrm{CH}_{3}\right)_{3} \mathrm{SnBr}_{3}$ & $\begin{array}{c}\mathrm{SnO} / \mathrm{NH}\left(\mathrm{CH}_{3}\right)_{3} \\
\mathrm{Cl}=1: 1\end{array}$ & $\mathrm{HBr}+\mathrm{H}_{3} \mathrm{PO}_{2}$ & 56-RT & One month & Colorless & $\begin{array}{c}8 \mathrm{~mm} \times 6 \mathrm{~mm} \times \\
4 \mathrm{~mm}\end{array}$ & \\
\hline & $\mathrm{MAPbI}_{3}$ & $\begin{array}{c}\mathrm{Pb}(\mathrm{Ac})_{2} \cdot 3\left(\mathrm{H}_{2} \mathrm{O}\right) / \\
\mathrm{MAI}=1: 1\end{array}$ & Aqueous $\mathrm{HI}$ & $65-40$ & $\begin{array}{l}\text { One } \\
\text { Month }\end{array}$ & Black & $\begin{array}{c}10 \mathrm{~mm} \times 10 \mathrm{~mm} \times \\
10 \mathrm{~mm}\end{array}$ & {$[64]$} \\
\hline & $\mathrm{MAPbI}_{3}$ & $\begin{array}{c}\mathrm{Pb}(\mathrm{Ac})_{2} \cdot 3\left(\mathrm{H}_{2} \mathrm{O}\right), \\
\mathrm{CH}_{3} \mathrm{NH}_{2}\end{array}$ & $\mathrm{HI}$ & $100-57$ & $15 \mathrm{~d}$ & Black & $\begin{array}{c}12 \mathrm{~mm} \times 12 \mathrm{~mm} \times \\
7 \mathrm{~mm}\end{array}$ & [108] \\
\hline \multirow{3}{*}{ TSSG } & $\mathrm{MAPbI}_{3}$ & $\begin{array}{c}\mathrm{Pb}(\mathrm{Ac})_{2} \cdot 3\left(\mathrm{H}_{2} \mathrm{O}\right) / \\
\mathrm{CH}_{3} \mathrm{NH}_{2}=1: 2\end{array}$ & $\mathrm{HI}$ & 75 & Several days & Black & $\begin{array}{l}\text { largest size of } \\
\quad \sim 10 \mathrm{~mm}\end{array}$ & {$[103]$} \\
\hline & $\mathrm{MASnI}_{3}$ & $\mathrm{SnO} / \mathrm{MAI}=1: 1$ & $\mathrm{HI} / \mathrm{H}_{3} \mathrm{PO}_{2}=1: 1$ & 65 & One month & Black & $\begin{array}{c}20 \mathrm{~mm} \times 16 \mathrm{~mm} \times \\
10 \mathrm{~mm}\end{array}$ & \multirow[t]{2}{*}{115} \\
\hline & $\mathrm{FASnI}_{3}$ & $\mathrm{SnO} / \mathrm{FAAc}=1: 1$ & $\mathrm{HI} / \mathrm{H}_{3} \mathrm{PO}_{2}=1: 1$ & 60 & One month & Black & $\begin{array}{c}8 \mathrm{~mm} \times 6 \mathrm{~mm} \times \\
5 \mathrm{~mm}\end{array}$ & \\
\hline \multirow{6}{*}{ ITC } & $\mathrm{CsPbBr}_{3}$ & $\mathrm{CsBr} / \mathrm{PbBr}_{2}=1: 2$ & $\mathrm{DMSO}+\mathrm{DMF}$ & $100-120$ & $3 \mathrm{~h}$ & Orange & $\underset{\times 1 \mathrm{~mm}}{3 \mathrm{~mm} \times 2 \mathrm{~mm}}$ & {$[68]$} \\
\hline & $\mathrm{CsPbBr}_{3}$ & $\mathrm{CsBr} / \mathrm{PbBr}_{2}=1: 1$ & $\mathrm{MeOH}$ & $\mathrm{RT}-80$ & $6 \mathrm{~h}$ & Orange & Nearly $3 \mathrm{~mm}$ long & {$[67]$} \\
\hline & $\mathrm{CsPbBr}_{3}$ & $\mathrm{CsBr} / \mathrm{PbBr}_{2}=1: 2$ & $\begin{array}{c}\mathrm{DMSO}+\mathrm{CyOH} \\
+\mathrm{DMF}\end{array}$ & $90-110$ & Several hours & Orange & Nearly $8 \mathrm{~mm}$ long & [116] \\
\hline & $\mathrm{FAPbBr}_{3}$ & $\mathrm{FAPbBr}_{3}$ & $\mathrm{DMF} / \mathrm{GBL}=1: 1$ & $40-60$ & $5 \mathrm{~h}$ & Orange & Nearly $5 \mathrm{~mm}$ long & [105] \\
\hline & $\mathrm{FAPbI}_{3}$ & $\mathrm{FAPbI}_{3}$ & GBL & $20-115$ & $3 \mathrm{~h}$ & Black & $3 \mathrm{~mm}$ long & [105] \\
\hline & $\mathrm{MAPbI}_{3}$ & $\mathrm{PbI}_{2} / \mathrm{MAI}=1: 1$ & GBL & $50-100$ & $2 \mathrm{~d}$ & Black & $\begin{array}{c}120 \mathrm{~mm} \times 70 \mathrm{~mm} \\
\times 52 \mathrm{~mm} \text { and } \\
113 \mathrm{~mm} \times 58 \mathrm{~mm} \\
\times 52 \mathrm{~mm}\end{array}$ & [117] \\
\hline \multirow{8}{*}{ AVC } & $\mathrm{CsPbBr}{ }_{3}$ & $\mathrm{CsBr} / \mathrm{PbBr}_{2}=1: 1$ & $\mathrm{DMSO} / \mathrm{MeCN}$ & 50 & $48 \mathrm{~h}$ & orange & Nearly $5 \mathrm{~mm}$ long & {$[67]$} \\
\hline & $\mathrm{CsPbBr}{ }_{3}$ & $\begin{array}{c}\mathrm{CsBr} / \\
\mathrm{PbBr}_{2}=1.5: 1\end{array}$ & $\begin{array}{c}\mathrm{DMSO} / 50 \% \\
\mathrm{DMSO}+50 \% \\
\mathrm{MeOH}\end{array}$ & RT & $3-14 d$ & Orange & $\begin{array}{c}42 \mathrm{~mm} \times 5 \mathrm{~mm} \times \\
3 \mathrm{~mm}\end{array}$ & {$[104]$} \\
\hline & $\mathrm{MAPbBr}_{3}$ & $\mathrm{PbBr}_{2} / \mathrm{MABr}=1: 1$ & $\begin{array}{l}\text { DMF/ } \\
\text { Toluene }\end{array}$ & RT & $>3 \mathrm{~d}$ & Orange & $\begin{array}{c}1.4 \mathrm{~mm} \times 1.4 \mathrm{~mm} \times \\
0.7 \mathrm{~mm}\end{array}$ & {$[118]$} \\
\hline & $\mathrm{MAPbBr}_{3}$ & $\mathrm{PbBr}_{2} / \mathrm{MABr}=1: 1$ & $\mathrm{DMF} / \mathrm{DCM}$ & RT & Several days & Orange & A few millimeters & [119] \\
\hline & $\mathrm{MAPbBr}_{3}$ & $\mathrm{PbBr}_{2} / \mathrm{MABr}=1: 1$ & $\mathrm{DMF} / \mathrm{DMC}$ & 25 & $24 \mathrm{~h}$ & Orange & $\begin{array}{c}10 \mu \mathrm{m} \times 10 \mu \mathrm{m} \\
\times 300 \mathrm{~nm}\end{array}$ & {$[120]$} \\
\hline & $\mathrm{MAPbBr}_{3}$ & $\mathrm{PbBr}_{2} / \mathrm{MABr}=1: 1$ & DMF/DMC & 60 & Different time & Orange & - & {$[121]$} \\
\hline & $\mathrm{MAPbI}_{3}$ & $\mathrm{PbI}_{2} / \mathrm{MAI}=1: 1$ & $\mathrm{HI} / \mathrm{DE}^{\mathrm{b}}$ & RT & $2 \mathrm{~d}$ & Black & Nearly $1 \mathrm{~mm}$ long & {$[122]$} \\
\hline & $\mathrm{MAPbI}_{3}$ & $\mathrm{PbI}_{2} / \mathrm{MAI}=1: 1$ & $\mathrm{C}_{2} \mathrm{H}_{3} \mathrm{~N}+\mathrm{HI} / \mathrm{DE}$ & RT & $2 \mathrm{~d}$ & Black & - & [123] \\
\hline
\end{tabular}

a) RT, room temperature; b) DE, diethyl ether.

duced recombination. This method provided an effective way to prepare high-quality inorganic perovskites [28]. Yang's team [139] obtained the $\mathrm{MAPbI}_{3}$ perovskite by a one-step method. It is significant that a gas pump drying system was introduced to accelerate solvent evaporation in the preparation of $\mathrm{MAPbI}_{3}$ film. Li's team [140] obtained shiny and smooth $\mathrm{FA}_{0.81} \mathrm{MA}_{0.15} \mathrm{PbI}_{2.51} \mathrm{Br}_{0.45}$ crystalline perovskite films by introducing a simple vacuum- flash solution processing to the one-step method.

(2) Two-step method

Different from the traditional organic-inorganic hybrid perovskites, a convenient two-step method invented by Jin's team [138] to prepare inorganic perovskites, including $\mathrm{CsPbBr}, \mathrm{CsPbIr}_{2}$, and $\mathrm{CsPb}_{0.9} \mathrm{Sn}_{0.1} \mathrm{IBr}_{2}$, can be carried out without humidity control. The approximate preparation process is as follows: firstly, the solid pre- 

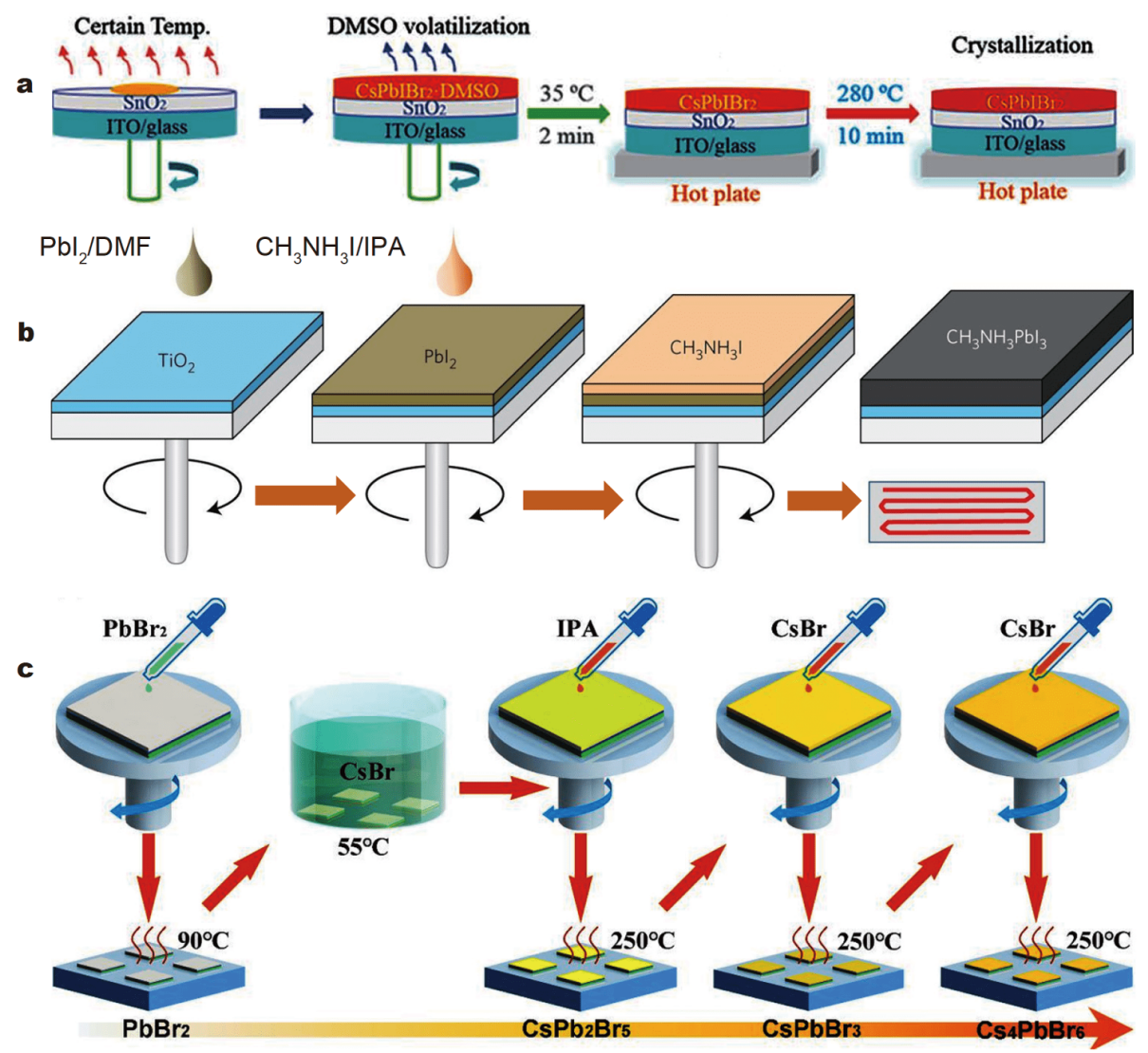

Figure 4 (a) One-step spin-coating method. Reprinted with permission from Ref. [28]. Copyright 2019, the Royal Society of Chemistry. (b) Two-step spin-coating method. Reprinted with permission from Ref. [93]. Copyright 2014, Springer Nature. (c) Multi-step spin-coating method. Reprinted with permission from Ref. [71]. Copyright 2019, Elsevier.

cursor $\left(\mathrm{PbBr}_{2}\right.$ for $\mathrm{CsPbBr}_{3}$ and $\mathrm{CsPbIr}_{2}$; or the mixture of $\mathrm{PbBr}_{2}$ and $\mathrm{SnBr}_{2}$ with a molar ratio of 0.9:0.1 for $\mathrm{CsPb}_{0.9} \mathrm{Sn}_{0.1} \mathrm{IBr}_{2}$ ) was dissolved in the mixed solvents of DMF and DMSO $(4: 1, v / v)$ under stirring at $80^{\circ} \mathrm{C}$ for $30 \mathrm{~min}$ to yield a $1.0 \mathrm{~mol} \mathrm{~L}^{-1}$ precursor solution. Then, the solution was deposited on the fluorine doped tin oxide $(\mathrm{FTO}) / \mathrm{c}-\mathrm{TiO}_{2} / \mathrm{m}-\mathrm{TiO}_{2}$ substrate by spin-coating at $2000 \mathrm{r} \mathrm{min}^{-1}$ for $30 \mathrm{~s}$, and dried at $80^{\circ} \mathrm{C}$ for $30 \mathrm{~min}$. After that, the prepared film was dipped in a $15 \mathrm{mg} \mathrm{mL}^{-1} \mathrm{me}-$ thanol solution of cesium salt ( $\mathrm{CsBr}$ for $\mathrm{CsPbBr}_{3}$; or CsI for $\mathrm{CsPbIBr}_{2}$ and $\mathrm{CsPb}_{0.9} \mathrm{Sn}_{0.1} \mathrm{IBr}_{2}$ ) for $10 \mathrm{~min}$. Subsequently, the as-obtained yellow films were thoroughly rinsed with isopropanol, and then heated for $10 \mathrm{~min}$ in air on a hotplate $\left(250^{\circ} \mathrm{C}\right.$ for $\mathrm{CsPbBr}_{3}$; or $350^{\circ} \mathrm{C}$ for $\mathrm{CsPbIBr}_{2}$ and $\left.\mathrm{CsPb}_{0.9} \mathrm{Sn}_{0.1} \mathrm{IBr}_{2}\right)$. Then, $\mathrm{CsPb}_{0.9} \mathrm{Sn}_{0.1} \mathrm{I}_{2} \mathrm{Br}$ and $\mathrm{Cs}_{0.9} \mathrm{MA}_{0.1} \mathrm{~Pb}_{0.9} \mathrm{Sn}_{0.1} \mathrm{IBr}_{2}$ films were also prepared by a similar process.

The growth of $\mathrm{CH}_{3} \mathrm{NH}_{3} \mathrm{PbI}_{3}$ cuboids can be realized with a controlled size by a two-step spin-coating method invented by Park's team. The average efficiency of the solar cell made from this $\mathrm{CH}_{3} \mathrm{NH}_{3} \mathrm{PbI}_{3}$ perovskite exceeded $16 \%$ and the best efficiency could reach $17 \%$. The two-step spin-coating procedure was described schematically in Fig. 4b [93].

Summarily, a $1 \mathrm{~mol} \mathrm{~L}^{-1}$ solution of $\mathrm{PbI}_{2}$ in $\mathrm{DMF}$ was initially spin-coated onto a $\mathrm{TiO}_{2}$ blocking layer with a mesoporous $\mathrm{TiO}_{2}$ film deposited. The $\mathrm{PbI}_{2}$-coated film was dried at $40^{\circ} \mathrm{C}$ for $3 \mathrm{~min}$ and $100^{\circ} \mathrm{C}$ for $5 \mathrm{~min}$. In the second step, different concentrations of $\mathrm{CH}_{3} \mathrm{NH}_{3} \mathrm{I}$ in 2propanol solution were spin-coated onto the $\mathrm{PbI}_{2}$ film and dried at $100^{\circ} \mathrm{C}$ for $5 \mathrm{~min}$ to form $\mathrm{MAPbI}_{3}$ [63]. They found that the size of the cuboid $\mathrm{CH}_{3} \mathrm{NH}_{3} \mathrm{PbI}_{3}$ was related to the concentration of $\mathrm{CH}_{3} \mathrm{NH}_{3} \mathrm{I}$ and its cuboid size significantly affected the charge-carrier extraction and light-harvesting efficiency [93]. Using a similar two-step spin-coating technique, Meng's team [141] first spincoated the mixed solution of $\mathrm{CH}_{3} \mathrm{NH}_{3} \mathrm{Cl}$ and $\mathrm{CH}_{3} \mathrm{NH}_{3} \mathrm{I}$ onto a $\mathrm{TiO}_{2} / \mathrm{PbI}_{2}$ film to form a controllable morphology of $\mathrm{CH}_{3} \mathrm{NH}_{3} \mathrm{PbI}_{3-x} \mathrm{Cl}_{x}$ film. They speculated that the existence of $\mathrm{CH}_{3} \mathrm{NH}_{3} \mathrm{Cl}$ would lead to preferential growth 
along the [110] direction of the perovskite, which could increase the crystallinity and surface coverage of the perovskite and reduce pinholes. Sang Il Seok's team [142] introduced additional iodide ions into the organic cation solution by the two-step method, which were used to form the perovskite layers through an intramolecular exchanging process, decreasing the concentration of the deep-level defect.

\section{(3) Multi-step method}

Owing to its excellent stability, especially thermal stability, the all-inorganic $\mathrm{Cs} \mathrm{PbBr}_{3}$ perovskite solar cell has attracted great attention in the photovoltaic field in recent years. However, bromide-rich perovskites, such as $\mathrm{Cs} \mathrm{PbBr}_{3}$, are always plagued by the low-phase purity and poor morphology of traditional two-step deposition methods $[17,18]$. Liao's team [71] demonstrated a simple and improved multi-step spin-coating process for manufacturing high-quality $\mathrm{CsPbr}_{3}$ films, as shown in Fig. 4c. The process of multi-step spin-coating method was as follows: firstly, the $\mathrm{PbBr}_{2}$ in DMF solution was spin-coated onto a substrate and annealed at $90^{\circ} \mathrm{C}$. Secondly, the $\mathrm{PbBr}_{2}$ film was immersed in a CsBr methanol solution maintained at $55^{\circ} \mathrm{C}$. Then, the formed $\mathrm{CsPbBr}_{3}$ film was washed with isopropyl alcohol, and annealed at $250^{\circ} \mathrm{C}$ to crystallize. Eventually, the surface of the $\mathrm{CsPbBr}$ film needed to be further spin-coated with $\mathrm{CsBr}$ methanol solution. Compared with the film prepared by the traditional two-step deposition process, the films prepared by the multi-step spin-coating method had higher homogeneity, higher $\mathrm{CsPbBr}_{3}$ phase purity, and larger average grain size (up to $1 \mu \mathrm{m}$ ). More importantly, not only the power conversion efficiency (PCE) of the $\mathrm{Cs} \mathrm{PbBr}_{3}$ perovskite solar cells was significantly boosted, but also the unencapsulated $\mathrm{CsPbBr}_{3}$ perovskite solar cell presented good humidity and thermal stability when stored in ambient air at room temperature $\left(25^{\circ} \mathrm{C}\right)$ for over $1000 \mathrm{~h}$ and at $60^{\circ} \mathrm{C}$ for one month, respectively. The multi-step spin-coating method provides a way for the practical application of efficient, cost-effective, and stable all-inorganic perovskite solar cells.

\section{Doping method}

The bromide compound, $\mathrm{MAPbBr}$, has a band gap of approximately $2.3 \mathrm{eV}$, and it is chosen as one of the candidates for visible laser and luminescence applications $[143,144]$. Photoluminescence quantum yield (PLQY) is an important indicator for both applications. A new doping method was invented by Sessolo's team [145] to produce the high-PLQY perovskite-based materials, whereby the stable alumina nanoparticles (NPs) were blended to the perovskite precursor. The $\mathrm{PbBr}_{2}$ and $\mathrm{MABr}$ were mixed together in a certain ratio and dissolved in DMF to form the precursor solution. Subsequently, an aqueous dispersion of $\mathrm{Al}_{2} \mathrm{O}_{3} \mathrm{NPs}$ with an average size of $10 \mathrm{~nm}$ was added to the perovskite precursor. The composite thin films can be prepared by spincoating the mixture solution on substrate in air, and then annealed on a hot plate at $90^{\circ} \mathrm{C}$ for $1 \mathrm{~h}$. The size of the nanocrystals depended on the concentration and size of the $\mathrm{Al}_{2} \mathrm{O}_{3}$ NPs. They found that the self-assembly of $\mathrm{Al}_{2} \mathrm{O}_{3} \mathrm{NPs}$ limited the growth of perovskite to nanoscale, which resulted in the spontaneous formation of isotropic $\mathrm{MAPbBr}_{3}$ nanocrystals. Therefore, a strong enhancement of photoluminescence can be observed. In addition, the material was simple to handle from the solution and insensitive to moisture, which made it become an interesting candidate for laser applications and luminescence.

Inorganic cesium lead perovskite $\left(\mathrm{CsPbI}_{3}\right)$ is a promising material that can prepare wide band gap perovskite solar cells, but it is unstable at room temperature. Therefore, the stabilization of the a-phase of $\mathrm{CsPbI}_{3}$ was one of the key prerequisites for its photovoltaic applications. A simple method to stabilize $\alpha$-phase $\mathrm{CsPbI}_{3}$ film by a single-step spin-coating process was reported by Huang's team [72], as shown in Fig. 5b, c. An equal molar ratio of $\mathrm{PbI}_{2}$ and CsI dissolved in the mixed solvent DMSO/DMF $(1: 4, v / v)$ to form the $\mathrm{CsPbI}_{3}$ precursor [72]. The $\mathrm{CsPbI}_{3}$ precursor solution was added to three different sulfobetaine zwitterions to stabilize the $a$-phase $\mathrm{CsPbI}_{3}$ film, as shown in Fig. 5b. They found that the best ratio of zwitterion added into $\mathrm{CsPbI}_{3}$ solution was $1.5 \%$, in which the $\alpha$-phase $\mathrm{CsPbI}_{3}$ film can be stabilized at room temperature. The interaction between zwitterions and $\mathrm{CsPbI}_{3}$ hindered the rapid crystallization of $\mathrm{CsPbI}_{3}$, such that the grain size of $\mathrm{CsPb}_{3}$ and the stabilization of the $\alpha$-phase could be reduced, as shown in Fig. $5 \mathrm{c}$. It was found that zwitterions prevented the crystallization of $\mathrm{CsPbI}_{3}$ perovskite films by electrostatic interaction with ions and colloids in the $\mathrm{CsPbI}_{3}$ precursor solution. The PCE of the solar cell using zwitterion-stabilized perovskite thin film can be attained at $11.4 \%$ under 1-sun illumination [72].

The long-chain ammonium salt additives were selected as the surface capping ligands during the one-step thin film spin coating by Jin's group [81], which could stabilize the metastable state during the film deposition of the $\mathrm{CsPbI}_{3}$ perovskite structure. It was found that different ammonium ligands can selectively stabilize two different perovskite polymorphs, including the cubic $\alpha-\mathrm{CsPbI}_{3}$ and the orthorhombic $\beta-\mathrm{CsPI}_{3}$ phase with distorted per- 
a

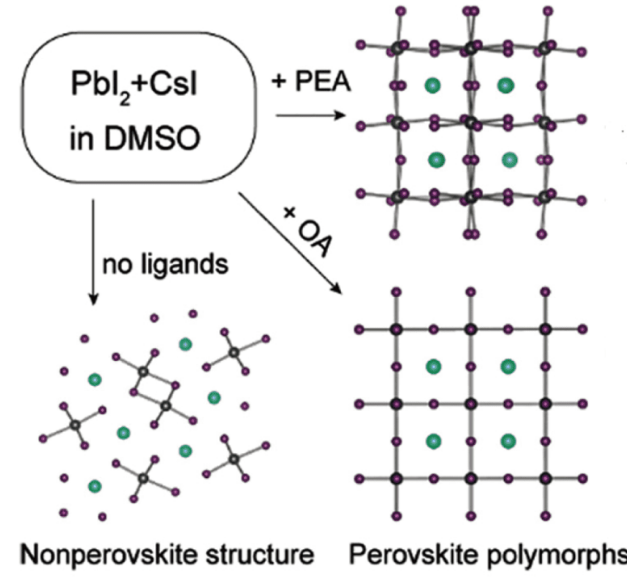

b

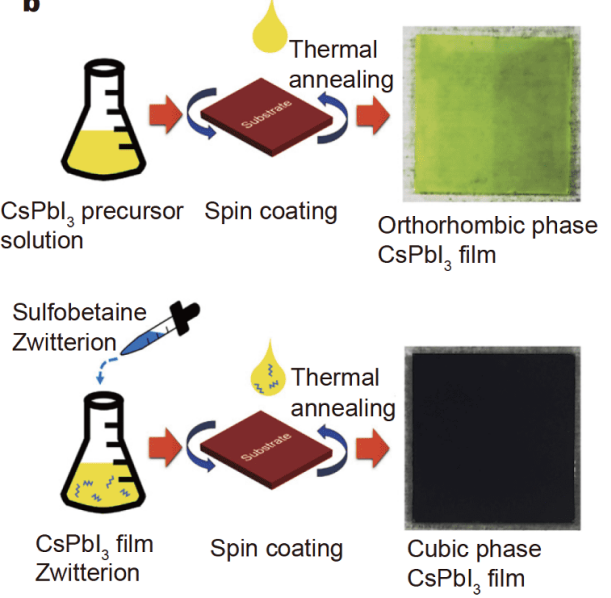

c

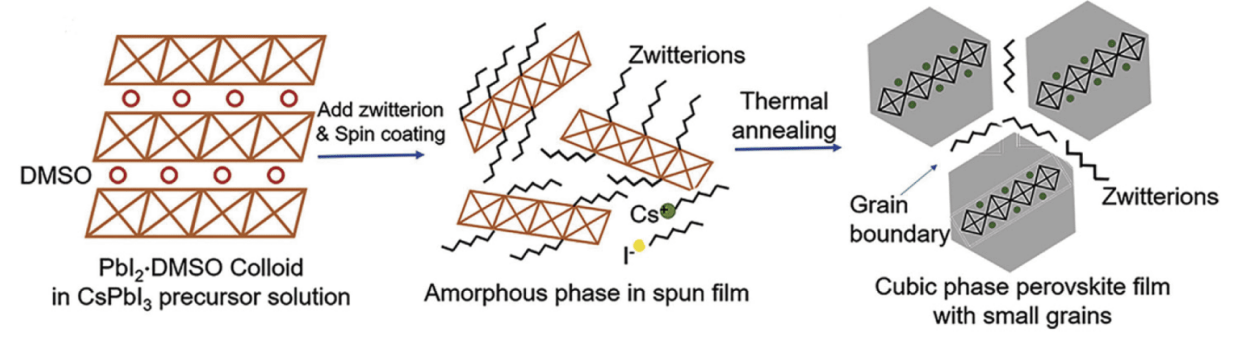

Figure 5 (a) Schematic illustration of hypothesized surface ligand functionalization of the $\mathrm{CsPbI}_{3}$ perovskite structures and structural characterizations of the stabilized $\mathrm{CsPbI}_{3}$ thin films. Reprinted with permission from Ref. [81]. Copyright 2017, the American Chemical Society. (b) The fabrication scheme of $\mathrm{CsPbI}_{3}$ film without/with zwitterions by one-step spin-coating. Reprinted with permission from Ref. [72]. Copyright 2017, Elsevier. (c) Schematic representation of $\mathrm{CsPbI}_{3}$ crystal formation from precursor solution with zwitterion. Reprinted with permission from Ref. [72]. Copyright 2017, Elsevier.

ovskite structure, as shown in Fig. 5a. Through surface functionalization, the $\mathrm{CsPbI}_{3}$ perovskite film had excellent room-temperature phase stability and exhibited good photophysical properties. It can be indicated that the spin-coating can provide a new way to obtain the optoelectronic devices based on $\mathrm{CsPbI}_{3}$ perovskites [81].

To get a film with more uniform and tightly distributed grains, $\mathrm{ZnO} \mathrm{NPs}$ were introduced into the $\mathrm{CsPbBr}_{3}$ precursor solution [70]. The $\mathrm{CsPbBr}_{3}$ and $\mathrm{CsPbBr}_{3}: \mathrm{ZnO}$ precursor needed to be prepared in an $\mathrm{N}_{2}$ glovebox. The $\mathrm{CsBr}$ and $\mathrm{PbBr}_{2}$ dissolved in the DMSO solvent to form the $\mathrm{CsPbBr}_{3}$ precursor solution. Adding $\mathrm{ZnO} \mathrm{NPs}$ to the $\mathrm{CsPbBr}{ }_{3}$ precursor solution at $60^{\circ} \mathrm{C}$ for $30 \mathrm{~min}$ can result in the formation of the $\mathrm{CsPbBr}_{3}: \mathrm{ZnO}$ precursor solution. The spin-coating process can improve the morphology and surface coverage of the film [69,146-148]. Therefore, the preparation of the $\mathrm{CsPbBr}_{3}$ and $\mathrm{CsPbBr}_{3}: \mathrm{ZnO}$ thin films introduced the spin-coating process. Through spin coating, the precursor solutions of the $\mathrm{CsPbBr}_{3}$ or $\mathrm{CsPbBr}: \mathrm{ZnO}$, the perovskite $\mathrm{CsPbBr}_{3}$ and $\mathrm{CsPbBr}_{3}: \mathrm{ZnO}$ films can be obtained. To wash away the DMSO from the perovskite wet film, $1 \mathrm{~mL}$ of chlorobenzene needs to be pipetted onto the substrate $(15 \mathrm{~s})$ before the last spincoating step $[69,147,148]$. To remove the residual DMSO solvent, an annealing process was also needed. The performance of photodetectors made with all-inorganic $\mathrm{CsPbBr}: \mathrm{ZnO}$ was better than that without $\mathrm{ZnO}$ doping [68].

Owing to its environmental stability, proper band gap, and distinctive color, $\mathrm{CsPbIBr}$ has broad photovoltaic application prospects. However, the defect states on the grain boundaries and the surface of the CsPbIBr${ }_{2}$ polycrystalline film can cause non-radiative carrier recombination, which reduces the final PCEs of its corresponding perovskite solar cells. Zheng's group [137] passivated the defect states of pure $\mathrm{CsPBIr}_{2}$ film by adding polyethylene glycol (PEG) into the precursor solution of $\mathrm{CsPbIBr}$ to improve the film morphology and coverage. Firstly, the precursor solution of $\mathrm{CsPbIBr}_{2}$ doped with a small amount of PEG was spin-coated on the corresponding substrate, and then, subsequently annealed to form a PEG-passivated $\mathrm{CsPbIBr}_{2}$ film. After 
introducing the PEG, not only the wettability of the precursor solution can be improved but also the coverage of the perovskite film on substrate can be enhanced owing to the three-dimensional (3D) network framework of PEG. In addition, the growth rate of the crystals can be slowed down and the aggregation of the perovskite crystals can be inhibited by the self-assembled PEG network in the process of the formation of the perovskite phase. In this way, it can effectively passivate the defect states at the surface and grain boundaries of $\mathrm{CsPbIBr} 2$ film, which can result in a more uniform perovskite film with fewer voids [137].

\section{Other methods of spin-coating}

\section{(1) Intermolecular exchange method}

To improve the quality of the $\mathrm{CsPbIBr}$ film, thereby optimizing the performance of solar cells, Zhang's group [149] introduced a simple and feasible method of intermolecular exchange during the preparation of $\mathrm{CsPbIr}_{2}$, as shown in Fig. 6a. Firstly, CsI and $\mathrm{PbBr}_{2}$ were dissolved in DMSO to form the CsPbIBr ${ }_{2}$ precursor. After spincoating the precursor, a transparent $\mathrm{CsPbIBr}{ }_{2}$ film can be formed on a compact substrate $[146,150]$. In the second step, $50 \mu \mathrm{L}$ of CsI solution was deposited onto the formed $\mathrm{CsPbIBr}{ }_{2}$ film by the spin-coating method. Since the CsI species has a higher affinity for $\mathrm{PbBr}_{2}$ than DMSO, thus, the intermolecular exchange of CsI and DMSO occurred at the same time in the process of the CsI solution spin- coating $[28,35,36]$. Finally, after washing with anhydrous isopropyl alcohol and annealing, high quality $\mathrm{CsPbIBr}_{2}$ films can be obtained. The main feature of this method was to spin-coat the optimized CsI methanol solution on the CsPbIBr $r_{2}$ membrane based on the conventional onestep spin-coating method. With merely this step of improvement, the prepared $\mathrm{CsPbIB}_{2}$ thin film has high phase purity, coverage and crystallinity, uniform particle size, as well as few grain boundaries.

(2) Solvent engineering method

A bilayer architecture that contained mesoscopic and planar structures was obtained by Seok's team [151] via the solvent-engineering process. This process that could be used to form uniform and dense perovskite layers, involved five stages. Initially, the mixture of the raw materials and the solvent in an appropriate ratio was spread on the entire surface of the substrate. Then, the spin coater was accelerated to the required rotation speed and held for a certain time to evaporate the solvent. The third key step was to drop a solvent (such as toluene or chloroform) that was miscible with both DMSO and GBL and did not dissolve the perovskite onto the substrate in the process of spinning, as shown in Fig. 6. Fourthly, the residual DMSO was removed and all components were frozen, and then a new complex could be formed as an intermediate phase. Lastly, the composite $\mathrm{CH}_{3} \mathrm{NH}_{3} \mathrm{~Pb}$ $\left(\mathrm{I}_{1-x} \mathrm{Br}_{x}\right)_{3} \quad(x=0.1-0.15)$ was transformed into a highly uniform crystalline perovskite after annealing. The key

a

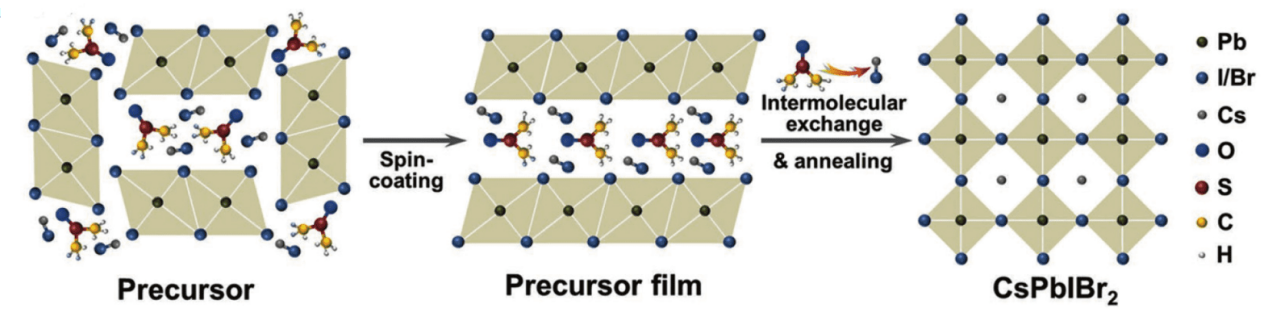

b

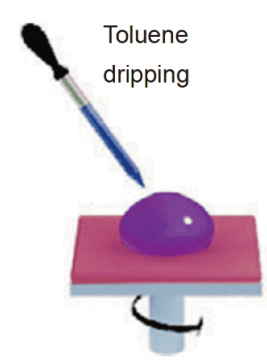

c

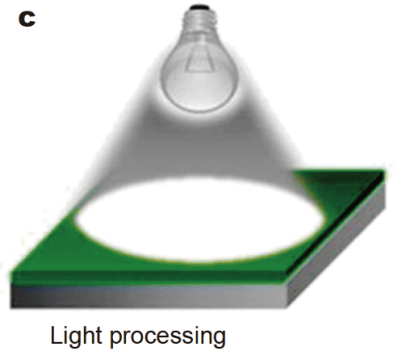

d

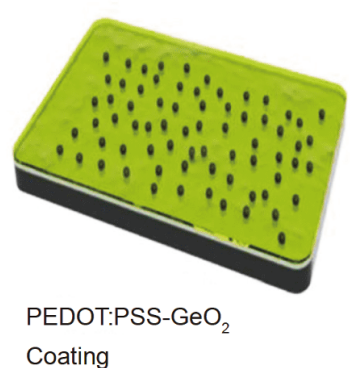

Figure 6 (a) Illustration of intermolecular exchange method. Reprinted with permission from Ref. [149]. Copyright 2018, Wiley. (b) Solvent engineering method. Reprinted with permission from Ref. [151]. Copyright 2014, Springer Nature. (c) Light-processing method. Reprinted with permission from Ref. [73]. Copyright 2019, the American Chemical Society. (d) Seed-mediated growth method. Reprinted with permission from Ref. [152]. Copyright 2016, the American Institute of Physics. 
technology of this method was to use a mixed solvent of GBL and DMSO, and then, dropwise add a toluene solvent treatment process to form a uniform and dense intermediate phase of the perovskite layer, which could provide a new way to realize low-cost and highly efficient perovskite solar cells.

\section{(3) Light-processing method}

$\mathrm{CsPbIBr}_{2}$ photovoltaic films with preferential orientation, high crystallinity, large size, full coverage, and pure phase were obtained by Zhang's team [73], using a lightprocessing technology, as shown in Fig. 6c. Initially, the precursor solution containing the raw material $\mathrm{PbBr}_{2}$, CsI, and solvent DMSO was spin-coated on a substrate in a glovebox to form the $\mathrm{CsPbIBr}$ precursor film. Then, the samples were treated with a simulated one-sun source for $60 \mathrm{~min}$ in ambient air atmosphere. The high-quality $\mathrm{CsPIBr}_{2}$ film was formed after the final annealing treatment. Compared with the film prepared by the conventional method, the obtained film by the lightprocessing method had a uniform morphology and was pinhole-free.

(4) Seed-mediated growth method

A seed-mediated method by $\mathrm{GeO}_{2} \mathrm{NPs}$ was used to grow high-quality perovskite crystal films reported by Wang's team [152], as shown in Fig. 6d. Firstly, the PEDOT:PSS- $\mathrm{GeO}_{2}$ composite precursor was spin-coated onto the ITO substrates. $\mathrm{GeO}_{2} \mathrm{NPs}$ of different sizes can be generated by adjusting the doping ratio of $\mathrm{GeO}_{2}$ and annealing conditions. $\mathrm{GeO}_{2} \mathrm{NPs}$ played the role of the growth point of crystal nucleus, and the perovskite on the bottom layer of substrate started to grow from $\mathrm{GeO}_{2} \mathrm{NPs}$. Finally, the high-quality perovskite films could be harvested by adjusting the size of $\mathrm{GeO}_{2} \mathrm{NPs}$ onto the substrate. The seed-mediated growth method of perovskite crystals provides a way for seeking other suitable NP materials in the future to make efficient and stable perovskite solar cells. In addition to the methods mentioned above, researchers are also constantly studying new methods, such as the interdiffusion [153] and slot-die coating methods [154], to explore the preparation of high-quality perovskite films for solar cells.

\section{CVD method}

CVD is a process widely used in industry, and is one of the many ways demonstrated for the vapor deposition of perovskites. Compared with perovskite films grown by solution, the perovskite materials grown by the CVD method have fewer defects and higher qualities. With the development of perovskite materials grown by CVD, different morphologies, such as platelets, films, micro- and nanowires (NWs), can be grown by controlling the growth conditions. In addition to changing the reaction conditions to obtain perovskite materials with different qualities, researchers also set up different reaction devices to study perovskite crystal materials. Because the growth conditions of organic-inorganic hybrid perovskite materials are quite different from the inorganic perovskite materials, the classification and summary are carried out herein.

\section{Growth of perovskite with different CVD devices}

The preparation of organic-inorganic hybrid perovskites and their potential applications mainly depend on the availability of their thin film deposition technology. Organic-inorganic hybrid materials usually cause organic components to decompose or dissociate at a temperature lower than that required for the evaporation of inorganic components during the gradual heating process, which makes it infeasible to prepare organic-inorganic hybrid perovskite materials using the single-source evaporation deposition technology.

In 1998, Mitzi and his coworkers [155] observed that the organic-inorganic hybrid crystals had reassembled in the original hybrid layer during the process of heating and cooling. This observation indicated that if the hybrid material was heated sufficiently fast, it was possible to deposit organic-inorganic thin films using a single evaporation source. Therefore, in 1999, Mitzi and his coworkers [155] used the prototype single source thermal ablation (SSTA) apparatus (Fig. 7a) to prepare several organic-inorganic hybrid perovskites, which included $\left(\mathrm{C}_{6} \mathrm{H}_{5} \mathrm{C}_{2} \mathrm{H}_{4} \mathrm{NH}_{3}\right)_{2} \mathrm{PbI}_{4},\left(\mathrm{C}_{6} \mathrm{H}_{5} \mathrm{C}_{2} \mathrm{H}_{4} \mathrm{NH}_{3}\right)_{2} \mathrm{PbBr}_{4}$, and $\left(\mathrm{C}_{4} \mathrm{H}_{9}-\right.$ $\left.\mathrm{NH}_{3}\right)_{2} \mathrm{SnI}_{4}$. These examples showed that the technique can be used in the preparation of a variety of organicinorganic hybrid perovskites with strong luminescence. In 2013, Snaith's group [62] created uniform flat films of the mixed halide perovskite $\mathrm{CH}_{3} \mathrm{NH}_{3} \mathrm{PbI}_{3-x} \mathrm{Cl}_{x}$ by dualsource vapor deposition. Fig. $7 \mathrm{~b}$ shows an illustration of the vapor-deposition set-up.

With the development of growth methods of perovskite materials, CVD devices have been improved continuously, such that high-quality perovskite materials with different morphologies can be grown. A CVD device with a single source and temperature zone is the most commonly used device for pure inorganic perovskite growth, as shown in Fig. 8a.

Generally, the heated $\mathrm{CsX}$ and $\mathrm{PbX}_{2}(\mathrm{X}=\mathrm{Cl}, \mathrm{Br}, \mathrm{I})$ mixture powder in the heated zone was used to obtain the $\mathrm{CsPbX}_{3}(\mathrm{X}=\mathrm{Cl}, \mathrm{Br}, \mathrm{I})$ ultrathin platelets [156], microspheres [157], oriented NWs and MWs [83], and so on. 


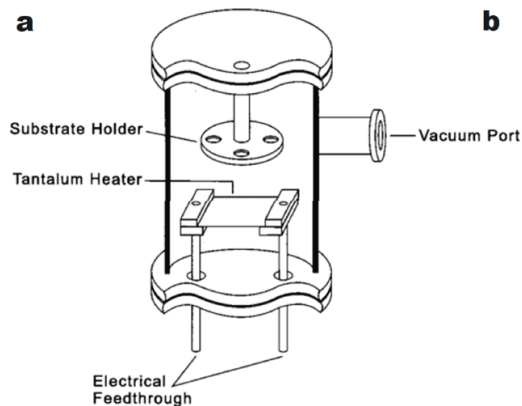

b

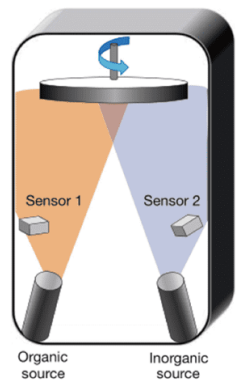

Figure 7 (a) Cross sectional view of a typical single source thermal ablation chamber. Reprinted with permission from Ref. [155]. Copyright 1999, American Chemical Society. (b) Dual-source thermal evaporation system for depositing the perovskite absorbers. Reprinted with permission from Ref. [62]. Copyright 2013, Springer Nature.

For example, Zeng's group [156] used van der Waals epitaxy to grow all-inorganic perovskite $\mathrm{CsPbBr}_{3}$ ultrathin platelets on different substrates to obtain materials with superb qualities. The source was the mixed powder of $\mathrm{PbBr}_{2}$ and $\mathrm{CsBr}$ in a molar ratio of $1: 1$. The mixed source and ultrathin mica were put in a quartz tube in a single zone furnace. The ultrathin mica was placed inside the downstream of the quartz tube. Afterward, highpurity $\operatorname{Ar}$ (99.99\%) was passed through the tube until the atmospheric pressure reached $10 \mathrm{~Pa}$. Keeping the flow rate of high-purity Ar at $35 \mathrm{sccm}$, the reaction was conducted under atmospheric pressure. The reaction temperature was increased from room temperature to $575^{\circ} \mathrm{C}$ within $20 \mathrm{~min}$, and the deposition lasted for $15 \mathrm{~min}$. Then, they obtained the $\mathrm{CsPbX}_{3}$ ultrathin platelets. Jin's team has developed a CVD system equipped with a mass flow controller and pressure control [82]. Using this system, they have grown high-quality horizontally oriented NWs and MWs of $\mathrm{CsPbX}_{3}(\mathrm{X}=\mathrm{Cl}, \mathrm{Br}$, or I) with high density on mica, as shown in Fig. 8b. This method is simple and versatile. Mica and muscovite mica were used as substrates and placed downstream in the cooling zone. The ground powders of $10 \mathrm{mmol} \mathrm{CsX}$ and $10 \mathrm{mmol} \mathrm{PbX}_{2}$ were mixed together and used as precursors for $\mathrm{CsPbX}_{3}$ and placed at the center of the heating zone. The distance between the precursor and the substrate was approximately $12 \mathrm{~cm}$. Argon gas was used as the carrier gas with a flow rate of $12 \mathrm{sccm}$ and the pressure inside the CVD tube was maintained at $80 \mathrm{mTorr}$. The temperature of the central heating zone varied with different halogens. The center of the heating zone was set to $300^{\circ} \mathrm{C}$ for the synthesis of $\mathrm{CsPbI}_{3}, 325^{\circ} \mathrm{C}$ for $\mathrm{CsPbBr}_{3}$, and $350^{\circ} \mathrm{C}$ for $\mathrm{CsPbl}_{3}$. The temperature at the substrate was approximately $40^{\circ} \mathrm{C}$ lower than that at the center of the heating zone measured by the thermocouple. According to the desired products, the CVD reactions were carried out from $5 \mathrm{~min}$ to up to $20 \mathrm{~h}$, and then, the furnace was cooled down naturally [83].

According to the different melting points of reactants and the desired morphologies of the products, sometimes the preparation of pure inorganic perovskite also needs
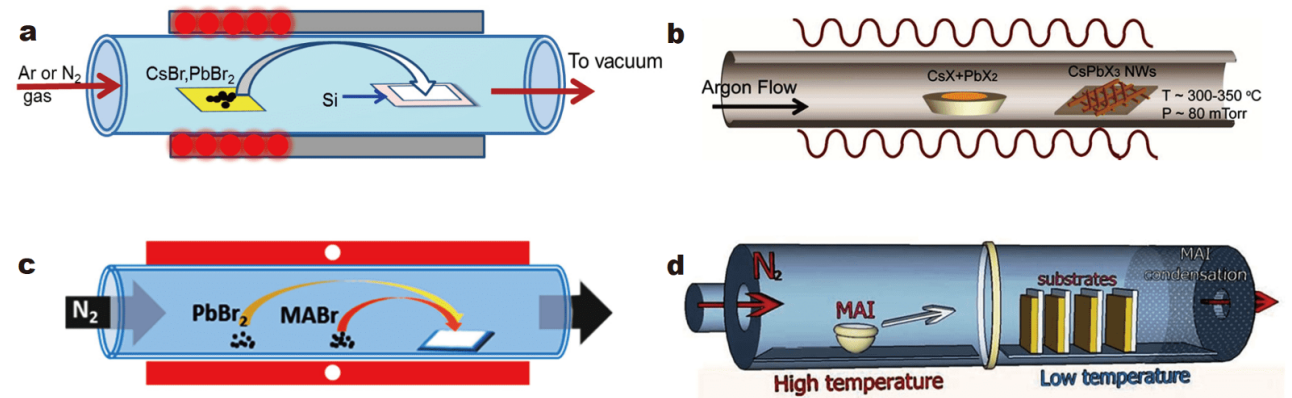

e

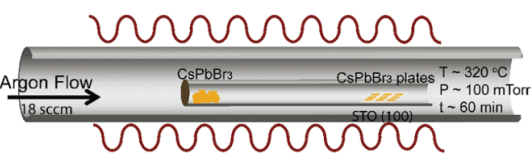

f

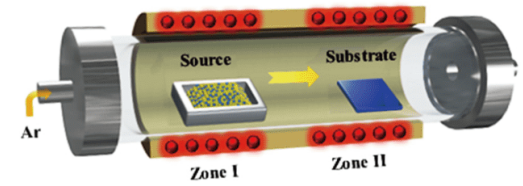

Figure 8 (a) CVD growth diagram of single heat source and single temperature zone [157]. (b) Schematic diagram of CVD to grow CsPbBr ${ }_{3} \mathrm{NWs}$ with single heat source. Reprinted with permission from Ref. [83]. Copyright 2016, the American Chemical Society. (c) Schematic diagram of growing $\mathrm{MAPbBr}_{3}$ using a dual heat source in a single-temperature-zone CVD device. Reprinted with permission from Ref. [76]. Copyright 2019, the American Chemical Society. (d) Diagram of the HCVD furnace and MAI deposition onto metal halide seeded substrates. Reprinted with permission from Ref. [99]. Copyright 2014, the Royal Society of Chemistry. (e) Schematic of growing CsPbBr 3 nanoplates on STO substrates with the tube-in-tube setup. Reprinted with permission from Ref. [84]. Copyright 2017, the American Chemical Society. (f) Schematic of growing CsPbBr ${ }_{3}$ microplatelets with single heat source and dual temperature zone. Reprinted with permission from Ref. [19]. Copyright 2018, the American Chemical Society. 
the choices of double sources and single-temperaturezone CVD systems. For example, Shi's group [158] achieved centimeter-scale single-crystalline thin film for inorganic halide perovskites of $\mathrm{CsBBr}_{3}(\mathrm{~B}=\mathrm{Pb}, \mathrm{Sn})$ on a $\mathrm{NaCl}$ substrate by vapor phase epitaxy (VPE). The cesium bromide powder $(\mathrm{CsBr})$ was placed in a heating furnace, whose temperature was controlled to approximately $500^{\circ} \mathrm{C}$, and lead (II) or tin (II) $\left(\mathrm{PbBr}_{2}, \mathrm{SnBr}_{2}\right)$ was placed in the upper stream approximately $10 \mathrm{~cm}$ away from the $\mathrm{CsBr}$ owing to its lower melting point. Then, the $\mathrm{NaCl}$ substrate was placed approximately $10 \mathrm{~cm}$ downstream from the heating zone. The base pressure was controlled to 0.5 Torr before deposition, and then, the flow rate of Argon carrier gas reached $30 \mathrm{sccm}$, which maintained the pressure at 0.7 Torr before deposition. It only took $7 \mathrm{~min}$ to raise the temperature from room temperature to the deposition temperature. According to the thickness of the film before shutting down the furnace, the deposition time can be maintained for 5-20 min. The furnace needed to be cooled to approximately $90^{\circ} \mathrm{C}$ before removing the $\mathrm{NaCl}$ substrate. During the growth process, the $\mathrm{NaCl}$ substrate was tilted $45^{\circ}$ to ensure uniform coating by the CVD process [158]. Wu's group [76] grew single-crystal platelets of $\mathrm{MAPbBr}_{3}$ on mica substrates by one-step CVD in a single-zone furnace, as shown in Fig. 8c. Square-shaped perovskite platelets were grown on the mica substrate at a pressure of 140 Torr and a growth temperature of $320^{\circ} \mathrm{C}$ in $20 \mathrm{~min}$. The lateral size of the obtained platelets can reach $10 \mu \mathrm{m}$, and their surface is uniform and smooth.

Among many photovoltaic materials, organic-inorganic perovskite films have attracted great attention from researchers due to their good performance in highefficiency solar cells. Zheng Liu's team cooperated with Xinfeng Liu [77] to explore the growth of perovskite $\mathrm{MAPbI}_{3}$ nanoplatelets on $\mathrm{SiO}_{2} / \mathrm{Si}$ substrates by a simple two-step CVD method. As shown in Fig. 8d, highly crystalline $\mathrm{PbI}_{2}$ nanoplatelets were first grown on the $\mathrm{Si} /$ $\mathrm{SiO}_{2}$ substrate by physical vapor deposition. Then, the $\mathrm{PbI}_{2}$ crystals were converted into perovskite by the reaction with $\mathrm{CH}_{3} \mathrm{NH}_{3} \mathrm{I}$ in vacuum. The size and thickness of the synthesized lead halide perovskite series nanoplatelets can be controlled by adjusting the growth temperature and time of $\mathrm{PbI}_{2}$ [77]. A new two-step method invented by Qi's team [99], as shown in Fig. 8d, which was used to synthesize perovskite by HCVD, could be easier to prepare and repeat the attainment of high-quality perovskite films. Furthermore, Surya's group [78] conducted an indepth study. In the first step, a layer of $\mathrm{PbX}_{2}(\mathrm{X}=\mathrm{Cl}, \mathrm{I}, \mathrm{Br})$, dissolved in DFM solution, was spin-coated onto the substrate. The pre-processed substrate and MAX or FAX $(\mathrm{X}=\mathrm{Cl}, \mathrm{Br}, \mathrm{I})$ were then loaded into two independent temperature-controlled zones of the furnace [159]. But the power of MAX or FAX $(\mathrm{X}=\mathrm{Cl}, \mathrm{Br}, \mathrm{I})$ need to be maintained at $T_{1}$, for example, usually $T_{\mathrm{MAI}}=180^{\circ} \mathrm{C}$. The pre-processed substrate was placed downstream to the MAX or FAX (X=Cl, Br, I). The sublimated MAX or FAX $(\mathrm{X}=\mathrm{Cl}, \mathrm{Br}, \mathrm{I})$ was transported by carrier gas to a predetermined area, which crystallized the $\mathrm{MAPbX}_{3}$ or $\mathrm{FAPbX}_{3}$ film. The diffusion of MAX or FAX $(\mathrm{X}=\mathrm{Cl}, \mathrm{Br}, \mathrm{I})$ took place in two phases. In the HCVD method, the MAX or FAX $(\mathrm{X}=\mathrm{Cl}, \mathrm{Br}, \mathrm{I})$ can diffuse into the substrate in gas phase.

To react with the metal halide present on the bottom surface to form a perovskite film, the MAX or FAX $(\mathrm{X}=\mathrm{Cl}, \mathrm{Br}, \mathrm{I})$ must diffuse through the film (i.e., solid diffusion). Surya's team [78] found that higher temperatures could increase the rate of gas and solid diffusion, as well as the rate of perovskite conversion. Multi-region HCVD has independent and precise control over the pressure, carrier gas type, gas flow rate, raw material, and substrate temperature, which helps to improve its reproducibility and perovskite film performance. A new HPCVD method was introduced by Cui's group [96] to synthesize high-quality perovskite films of $\mathrm{CH}_{3} \mathrm{NH}_{3} \mathrm{PbI}_{3}$. Compared with published vapor-based methods, $\mathrm{CH}_{3}$ $\mathrm{NH}_{3} \mathrm{PbI}_{3}$ thin films were synthesized in a well-controlled vacuum and isothermal environment. Critical reaction parameters, including vapor pressure and reaction temperature, can be adjusted accurately to further improve the perovskite film quality. This method is compatible with traditional semiconductor manufacturing methods, and can obtain high-quality perovskite films through accurate process control. Eventually, perovskite-based solar cells can achieve low-cost, large-scale production.

To grow perovskite materials with different morphologies and high qualities, the device for growing perovskite materials is also constantly upgrading and improving. A micrometer-thick $\mathrm{CsPbBr}_{3}$ single-crystal array film was grown on conventional $\mathrm{SrTiO}_{3}$ (100) substrates via VPE, which was first reported by Jin's group [84]. The growth of the epitaxial $\mathrm{CsPbBr}$ nanoplates and single-crystal thin films was carried out in a home-built "tube-in-tube" CVD setup that was equipped with mass flow controllers and pressure control, as shown in Fig. 8e. The inner diameters of the outer and inner tubes are 2.1 and $1.2 \mathrm{~cm}$, respectively. This "tube-in-tube" setup with the sealed end of the inner tube facing the carrier gas flow direction helps to maintain a steady laminar flow in the reactor for controlled growth. Initially, $\mathrm{Cs}_{\mathrm{PbBr}}$ ingots were pre- 
pared by melting $\mathrm{CsBr}$ and $\mathrm{PbBr}_{2}$ (in 1:1 molar ratio) at $550^{\circ} \mathrm{C}$ under atmosphere pressure, and then used as the precursor for the epitaxial growth. Then the $\mathrm{CsPbBr}$ ingots were placed at the center of the heating zone inside the inner tube close to the sealed end of the inner tube. The $\mathrm{SrTiO}_{3}(100)$ substrates were placed downstream at the cooling zone closer to the open end of the inner tube. The distance between the precursor and the $\mathrm{SrTiO}_{3}$ (STO) substrate was approximately $12 \mathrm{~cm}$. The pressure of the argon carrier gas inside the CVD tube was maintained at $100 \mathrm{mTorr}$, and the flow rate of $\mathrm{Ar}$ was $18 \mathrm{sccm}$. For the typical growth of $\mathrm{CsPBr}_{3}$ nanoplate arrays, the CVD reactions were carried out for $60 \mathrm{~min}$ with the center of the heating zone (where the $\mathrm{Cs} \mathrm{PbBr}_{3}$ precursor was) set to $320^{\circ} \mathrm{C}$, as shown in Fig. 8e. For the successful growth of continuous $\mathrm{CsPbr}_{3}$ single-crystal thin films, the CVD reactions were run at $450^{\circ} \mathrm{C}$ (the temperature of the precursor) for 12-20 min, depending on the desired thickness. Once the reaction was finished, the furnace was turned off and allowed to cool naturally to room temperature [84].

A dual-temperature zone tube furnace was used as a reactor to synthesize high-quality micrometer-scale inorganic $\mathrm{CsPbBr}_{3}$ microplatelets by Shi's team [19] using the CVD method, as shown in Fig. 8f. According to the molar ratio of $1: 2$, the $\mathrm{CsBr}$ and $\mathrm{PbBr}_{2}$ powders were mixed together and formed the precursors, which were placed in the zone I of the tube furnace and heated to $580^{\circ} \mathrm{C}$. The substrate $\mathrm{SiO}_{2} / \mathrm{Si}$ was also placed in the zone II of the tube furnace and needed to be heated to $360^{\circ} \mathrm{C}$, which was different from that of the single zone furnace. After adjusting the two zones to the predetermined temperature and pressure, and keeping the deposition for 20 min, the $\mathrm{CsPbBr}_{3}$ microplatelets on the $\mathrm{SiO}_{2} / \mathrm{Si}$ substrate can be harvested [19].

To remove toxic $\mathrm{Pb}$, perovskite materials based on $\mathrm{Sn}$ or Bi cations have also been studied extensively. For example, a CVD reactor developed by Sanders's team [160] can simultaneously deposit solvent-free precursors of MAI and $\mathrm{BiI}_{3}$ under low vacuum, which was a deposition tool based on the showerhead and was the first application to the growth of perovskite, as shown in Fig. 9. The CVD reactor can provide precise process control, making it possible for large-area production. Nitrogen was used as the protective gas, and the $\mathrm{N}_{2}$ flow was set to $500 \mathrm{sccm}$. To avoid cross-contamination, $\mathrm{BiI}_{3}$ and MAI were placed in two different crucibles to form evaporation sources. According to the $\mathrm{MAI} / \mathrm{BiI}_{3}$ ratio and the crucible filling amount, the $\mathrm{BiI}_{3}$ crucible needed to be heated to $240-$ $270^{\circ} \mathrm{C}$, and the MAI crucible was heated to $180-200^{\circ} \mathrm{C}$.

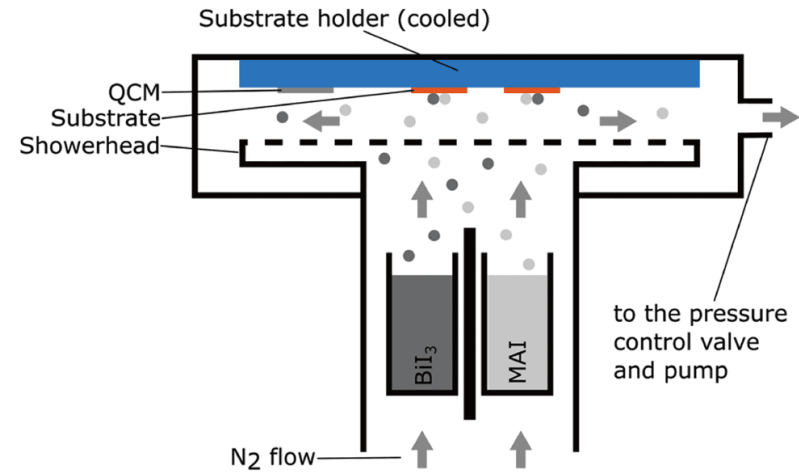

Figure 9 Schematic illustration of showerhead-based deposition tool for the growth of perovskites. Reprinted with permission from Ref. [160]. Copyright 2019, Springer Nature.

Generally, the gas mixture of sublimed molecules and carrier gas be dispersed when the showerhead was maintained at $260^{\circ} \mathrm{C}$, such that it could be uniformly deposited on substrates with an area of $108 \mathrm{~cm}^{2}$ $(12 \mathrm{~cm} \times 9 \mathrm{~cm})$. They not only studied the effect of precursor velocity on the layer morphology and optical and crystallographic properties by changing the ratio of MAI/ $\mathrm{BiI}_{3}$ precursor, but also investigated the effect of substrate temperature and layer thickness on the morphology of methylammonium bismuth iodide (MBI) crystalline by changing the temperature.

Effect of growth conditions on the morphology of perovskite With the change of growth conditions (growth temperature, pressure, time, substrate, etc.), perovskite materials with different morphologies, such as triangles, squares, hexagomacro/nanoplatelets [161,76,7], triangular pyramid nanocrystals [85], micro/nanorods [30], NWs with a square end facet [162], nanospheres [157], and nano-array [84], can be grown by the CVD method, as shown in Fig. 10a-h.

Wu's team worked in conjunction with Liu [74] to investigate the effect of the pressure of the carrier gas and temperature of the source on the morphology of $\mathrm{MAPbBr}_{3}$ platelets. Fig. 11a presents the change of crystal morphology with growth conditions. The growth time was kept the same. The square-shaped platelets cannot be obtained at the lower pressure and growth temperature. For example, 3D spheres with a uniform diameter can be observed at 100 Torr and $320^{\circ} \mathrm{C}$. Then, the $2 \mathrm{D}$ platelets and $3 \mathrm{D}$ spheres coexisting can be observed with the increase of pressure (Fig. $11 \mathrm{a}_{2}$ ). With continued pressure increase, the 3D spheres finally disappeared (Fig. 11 $\mathrm{a}_{3}$ ), which indicated a transition between the pressure- 

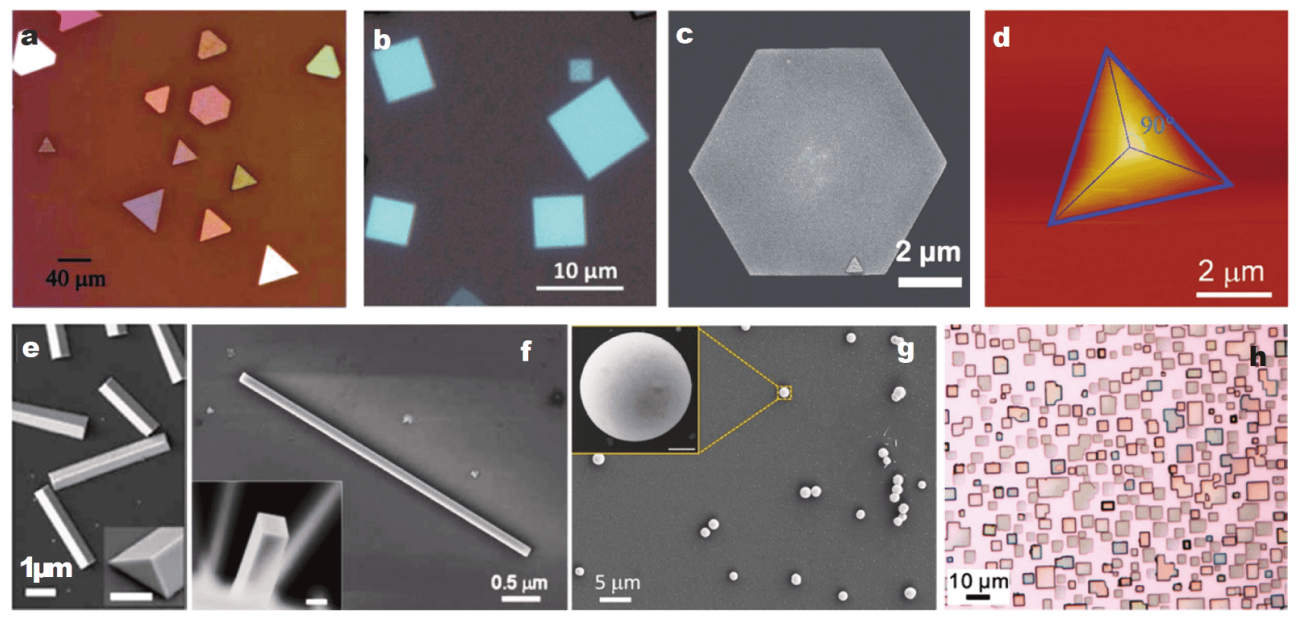

Figure 10 (a) Growth of triangular $\mathrm{MAPbI}_{3}$ nanoplatelets on the mica substrate. Reprinted with permission from Ref. [161]. Copyright 2019, Wiley. (b) Growth of square $\mathrm{MAPbBr}_{3}$ single-crystal platelet. Reprinted with permission from Ref. [76]. Copyright 2019, the American Chemical Society. (c) Growth of hexagonal $\mathrm{MAPbI}_{3}$ nanoplatelets on the $\mathrm{Si}_{/} \mathrm{SiO}_{2}$ substrate. Reprinted with permission from Ref. [77]. Copyright 2016, Wiley. (d) Growth of a typical $\mathrm{MAPbBr}_{3}$ triangular pyramid nanocrystal on a mica substrate. Reprinted with permission from Ref. [85]. Copyright 2018, Wiley. (e) Growth of the $\mathrm{CsPbBr}_{3}$ micro/nanorods. Reprinted with permission from Ref. [30]. Copyright 2016, the American Chemical Society. (f) Growth of a typical nanowire with a square end facet. Reprinted with permission from Ref. [162]. Copyright 2018, Wiley. (g) Growth of the CsPbBr 3 microcrystals on the silicon wafer with a spherical shape. Reprinted with permission from Ref. [157]. Copyright 2019, the Royal Society of Chemistry. (h) Growth of $\mathrm{CsPbr}_{3}$ nanoplates on the STO(100) substrate. Reprinted with permission from Ref. [84]. Copyright 2017, the American Chemical Society.

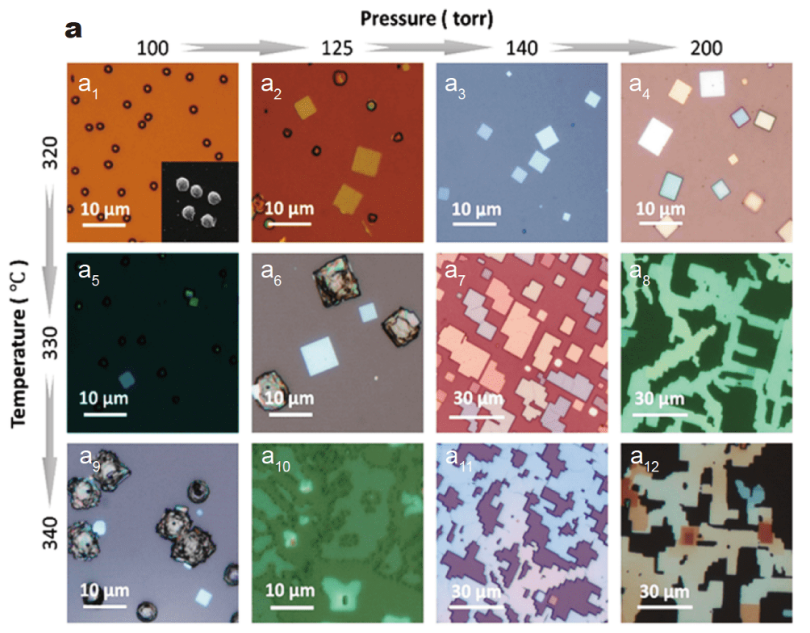

b

c
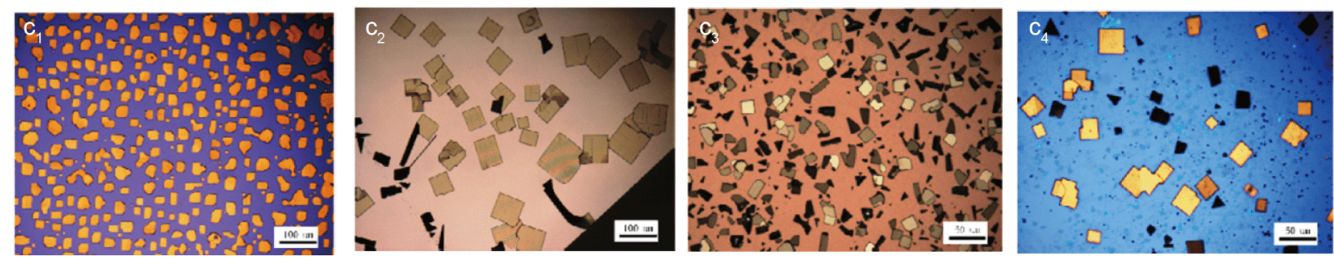

Figure 11 (a) Effects of temperature and pressure on the morphology of perovskite crystals. Reprinted with permission from Ref. [76]. Copyright 2019, the American Chemical Society. (b) Scanning electron microscope (SEM) images of the Cs $\mathrm{PbBr}_{3} \mathrm{NWs}$ and MWs, networks, and continuous film grown on p-mica with different reaction times from $5 \mathrm{~min}$ to $20 \mathrm{~h}$. Reprinted with permission from Ref. [83]. Copyright 2016, the American Chemical Society. (c) Optical images of $\mathrm{CsPbBr}$ ultrathin platelets on different substrates $\left(\mathrm{c}_{1}\right) \mathrm{SiO}_{2} / \mathrm{Si},\left(\mathrm{c}_{2}\right) \mathrm{GaN},\left(c_{3}\right)$ FTO glass, $\left(\mathrm{c}_{4}\right)$ graphene. Reprinted with permission from Ref. [156]. Copyright 2017, the American Chemical Society. 
induced $2 \mathrm{D}$ and $3 \mathrm{D}$ nucleation modes. At a high pressure of 200 Torr, larger and thicker platelets could be observed, which showed that growth rate was also related to pressure.

The growth temperature also has an important effect on the morphology of the perovskite. Upon increasing the furnace temperature from 320 to $330^{\circ} \mathrm{C}$, nearly no platelets can be observed at lower pressure (Fig. 11a 5 ), and some irregular structures appeared with the pressure increasing to 125 Torr (Fig. $11 \mathrm{a}_{6}$ ). When the temperature was kept at $330^{\circ} \mathrm{C}$, and the pressure changed, the formation of the larger perovskite structures, which consisted of connected square platelets, could be observed (Fig. $11 a_{7}, a_{8}$ ). On increasing the temperature further to $340^{\circ} \mathrm{C}$ (Fig. $11 \mathrm{a}_{9}-\mathrm{a}_{12}$ ), a similar evolution of the perovskite morphology with that at $330^{\circ} \mathrm{C}$ was observed, except that the platelets tended to connect together and formed thick terrace structures. Finally, it can be observed the platelets can be broken down into amorphous structures at high growth temperatures and low pressures (e.g., Fig. $11 \mathrm{a}_{5}, \mathrm{a}_{6}$, $\left.a_{9}, a_{10}\right)[76]$.

In cooperation with Wu's group, Mi et al. [85] found that the growth temperature had a great effect on the morphology of $\mathrm{MAPbBr}_{3}$ single crystals in the growth process of pyramid-shaped $\mathrm{MAPbBr}_{3}$ by the CVD method, as shown in Fig. 10d. Generally, the center temperature was set at $345^{\circ} \mathrm{C}$ in the growth process. On slightly increasing the growth temperature $\left(10^{\circ} \mathrm{C}\right)$, they found that the top of the pyramids would be flat with some concave cubic corners. When Jin's team [83] used a "tube-in-tube" CVD device to grow $\mathrm{CsPbBr}_{3}$ single crystal thin films, they found that increasing the reaction temperature was the key to realize the continuous growth of $\mathrm{Cs} \mathrm{PbBr}_{3}$ single crystals. Increasing the temperature not only enhanced the diffusion of adsorbed atoms but also accelerated the nucleation of the preferred epitaxial crystals.

The growth time in CVD also has significant influence on the quality and the morphology of perovskite materials. Jin's group [83] synthesized $\mathrm{CsPbX}_{3}(\mathrm{X}=\mathrm{Cl}, \mathrm{Br}, \mathrm{I})$ NWs and MWs by a modified CVD system. When the deposition time changed from $5 \mathrm{~min}$ to $20 \mathrm{~h}$, a variety of $\mathrm{CsPbBr}{ }_{3}$ nanostructures could be obtained, such as single NWs, Y-shaped branches, and interconnected NW or MW networks, as shown in Fig. 11b.

In the growth process of the cube-cornered $\mathrm{CH}_{3} \mathrm{NH}_{3}$ $\mathrm{PbBr}_{3}$ pyramids, Mi et al. [85] found that the sizes of the cube-cornered $\mathrm{CH}_{3} \mathrm{NH}_{3} \mathrm{PbBr}_{3}$ pyramids could be controlled accurately with slight deviations in the growth time. When the growth temperature was kept at $345^{\circ} \mathrm{C}$, the size of the pyramids increased with the growth time. At a growth time of $15 \mathrm{~min}$, small pyramids with a uniform lateral size of $2 \mu \mathrm{m}$ can be distinguished. However, with the growth time increasing to $30 \mathrm{~min}$, large pyramids with a lateral size of approximately $10 \mu \mathrm{m}$ can be found among the small pyramids. Additionally, with a longer growth time, the size distribution would not be as uniform as that with a shorter growth time. The reason could be that smaller pyramids were formed at a later time compared with the larger ones.

The substrate also affects the morphology and quality of the crystal. For example, Zeng's group [156] not only obtained the $\mathrm{CsPbBr}_{3}$ ultrathin platelets on ultrathin mica by the CVD method, but also grew the $\mathrm{CsPbr}_{3}$ ultrathin platelets on different substrates, including graphene, GaN, FTO glass, and $\mathrm{SiO}_{2} / \mathrm{Si}$, as shown in Fig. 11c. It can be seen from Fig. 11c that the morphologies and qualities of the $\mathrm{CsPBrr}_{3}$ ultrathin platelets are different with various substrates.

The key step in realizing practical optoelectronic devices was to control the growth or patterning of perovskite components on ubiquitous silicon optoelectronic platforms. By pre-patterning a single-layer hexagonal boron nitride (h-BN) buffer layer, Liu's group [163] obtained high-quality patterned perovskite arrays on $\mathrm{Si}$ substrate for lasing and light emission via a novel bottomup growth technique, as shown in Fig. 12.

The BN films were synthesized on $\mathrm{Cu}$ foil by the CVD method. Initially, the BN films were transferred to the $\mathrm{SiO}_{2} / \mathrm{Si}$ substrates in a standard transfer method. Then, using standard photo-lithography methods, the large-area BN film (wafer scale) was patterned. Finally, a single-layer BN film was used as a buffer layer, and a high-quality halide perovskite-type microcrystalline array was prepared on a silicon substrate by a two-step CVD method. It can be seen that the quality and morphology of perovskite materials are greatly affected by the growth device, growth conditions, and growth process. Therefore, to prepare perovskite materials with different morphologies and halides, the required conditions will be different.

Xiong's group $[31,164]$ synthesized high-quality crystalline $\mathrm{CH}_{3} \mathrm{NH}_{3} \mathrm{PbI}_{3}, \mathrm{CH}_{3} \mathrm{NH}_{3} \mathrm{PbBr}_{3}, \mathrm{CH}_{3} \mathrm{NH}_{3} \mathrm{PbCl}_{3}, \mathrm{CH}_{3}$ $\mathrm{NH}_{3} \mathrm{PbI}_{x} \mathrm{Cl}_{3-x}, \mathrm{CH}_{3} \mathrm{NH}_{3} \mathrm{PbI}_{x} \mathrm{Br}_{3-x}$, and $\mathrm{CH}_{3} \mathrm{NH}_{3} \mathrm{PbBr}_{x} \mathrm{Cl}_{3-x}$ platelets and NWs by adjusting the precursor, reaction temperature, and pressure via a two-step vapor phase method. Firstly, $\mathrm{PbX}_{2}(\mathrm{X}=\mathrm{I}, \mathrm{Br}$, or $\mathrm{Cl})$ platelets or NWs were prepared on mica substrate by the CVD method. Secondly, using $\mathrm{PbX}_{2} / \mathrm{CH}_{3} \mathrm{NH}_{3} \mathrm{X}(\mathrm{X}=\mathrm{I}, \mathrm{Br}$, or $\mathrm{Cl})$ as the reaction precursor, the organic-inorganic hybrid per- 


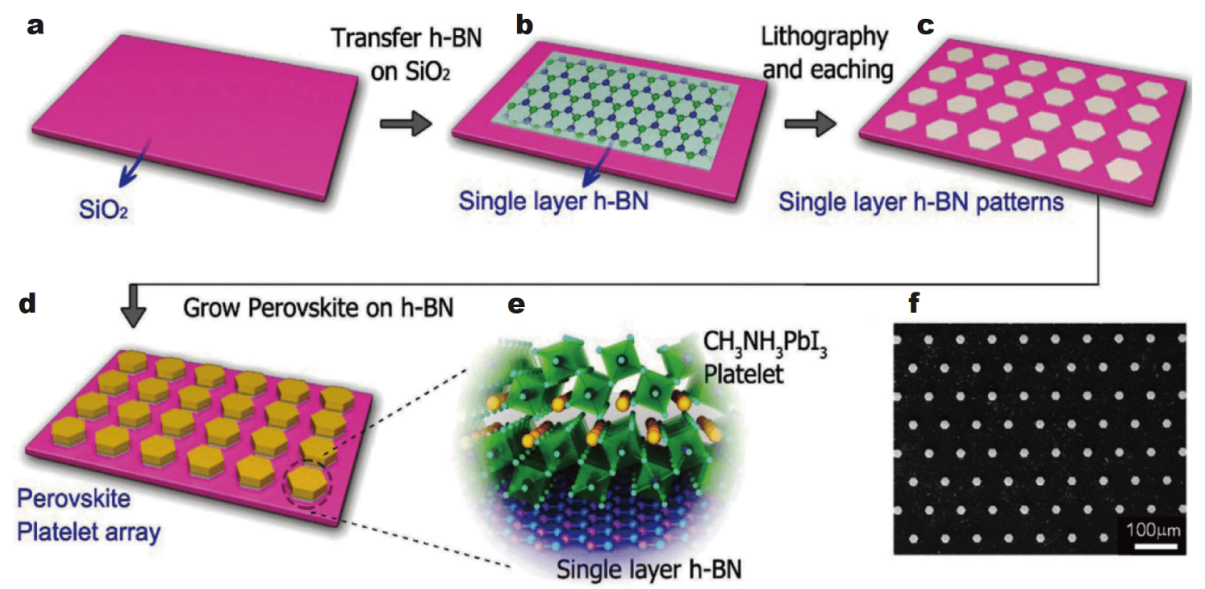

Figure 12 Fabrication process for the perovskite platelet array and SEM image of the as-prepared $\mathrm{CH}_{3} \mathrm{NH}_{3} \mathrm{PbX}_{3}(\mathrm{X}=\mathrm{Cl}, \mathrm{Br}, \mathrm{I})$ platelet array. Reprinted with permission from Ref. [163]. Copyright 2016, Wiley.

ovskite was prepared by the CVD method with Ar or $\mathrm{N}_{2}$ as the protective gas. However, for the synthesis of $\mathrm{PbX}_{2}$, the mica substrate needed to be put in the downstream zone of the quartz tube. Furthermore, the $\mathrm{CH}_{3} \mathrm{NH}_{3} \mathrm{X}$ $(\mathrm{X}=\mathrm{I}, \mathrm{Br}$, or $\mathrm{Cl})$, prepared by a solution method, was used as a source, and it needed to be placed in the center of the quartz tube, while the silicon wafer also had to be placed in the downstream region. Then, a similar CVD system was used to prepare the $\mathrm{CH}_{3} \mathrm{NH}_{3} \mathrm{PbX}(\mathrm{X}=\mathrm{I}, \mathrm{Br}$, or $\mathrm{Cl})$ NWs. Different halogens and crystal morphologies need different preparation temperatures and pressures $[31,164]$. The different specific preparation conditions are shown in Table 2.

Compared with organic-inorganic hybrid perovskites, the solubility of inorganic perovskites is lower. For example, the $\mathrm{Cs}-\mathrm{Pb}-\mathrm{X}$ phase diagram is more complicated, with three phases of $\mathrm{CsPbBr}_{3}, \mathrm{CsPb}_{2} \mathrm{Br}_{5}$, and $\mathrm{Cs}_{4} \mathrm{PbBr}_{6}$, such that the solution method used to grow inorganic perovskites is usually more difficult [66-68]. Therefore, there was an urgent need to develop an effective method to grow inorganic halide perovskite materials [84]. Xiong's [32], Jin's [83,84], Zhang's [75], and Liu's $[74,157,162]$ groups have done a lot of work on the growth of inorganic perovskite. For example, they prepared high-quality single-crystalline $\mathrm{CsPbX}_{3}(\mathrm{X}=\mathrm{Cl}, \mathrm{Br}, \mathrm{I})$ perovskite nanoplatelets on a muscovite mica substrate by a modified CVD system [32]. The detailed reaction conditions are shown in Table 3.

Through the change of growth conditions and devices, various perovskite materials with different morphologies can be grown by CVD, such as platelets, square sheets, triangular sheets, micro/nanowires, pyramids and micro/ nano spheres. Therefore, the CVD method can be used to grow high-quality perovskite materials with specific morphologies, according to the actual needs.

\section{CONCLUSIONS AND OUTLOOK}

The unique and excellent properties of metal halide perovskites, such as extended diffusion lengths, long carrier lifetimes, high wavelength tenability, high fluor-

Table 2 The preparation conditions of $\mathrm{MAPbX}_{3}$

\begin{tabular}{|c|c|c|c|c|c|c|c|c|c|c|}
\hline \multicolumn{5}{|c|}{ First-step } & \multicolumn{5}{|c|}{ Second-step } & \multirow[b]{2}{*}{ Ref. } \\
\hline Product & Protective gas & $\begin{array}{c}T \\
\left({ }^{\circ} \mathrm{C}\right)\end{array}$ & $\begin{array}{c}P \\
\text { (Torr) }\end{array}$ & $\begin{array}{l}\text { Time } \\
(\mathrm{min})\end{array}$ & Product & Protective gas & $\begin{array}{c}T \\
\left({ }^{\circ} \mathrm{C}\right)\end{array}$ & $\begin{array}{c}P \\
\text { (Torr) }\end{array}$ & $\begin{array}{l}\text { Time } \\
(\mathrm{min})\end{array}$ & \\
\hline $\mathrm{PbI}_{2}$ platelet & & 380 & 200 & 20 & $\mathrm{MAPbI}_{3}$ platelets & & & & & {$[31]$} \\
\hline $\mathrm{PbBr}_{2}$ platelets & & 350 & 75 & 20 & $\mathrm{MAPbBr}_{3}$ platelets & $\begin{array}{l}\text { High-purity Ar } \\
\text { or } \mathrm{N}_{2} \text { gas }\end{array}$ & 115 & 40 & 60 & {$[31]$} \\
\hline $\mathrm{PbCl}_{2}$ platelets & High-purity & 510 & 200 & 20 & $\mathrm{MAPbCl}_{3}$ platelets & & & & & {$[31]$} \\
\hline $\mathrm{PbI}_{2} \mathrm{NWs}$ & v) & 380 & 200 & 15 & $\mathrm{MAPbI}_{3}$ NWs & & 120 & & & [164] \\
\hline $\mathrm{PbBr}_{2} \mathrm{NWs}$ & & 350 & 50 & 15 & $\mathrm{MAPbBr}_{3} \mathrm{NWs}$ & $\begin{array}{l}\text { High-purity } \\
\mathrm{N}_{2} \text { gas }\end{array}$ & 120 & 50 & 60 & [164] \\
\hline $\mathrm{PbCl}_{2}$ NWs & & & & & $\mathrm{MAPbCl}_{3} \mathrm{NWs}$ & & 100 & & & [164] \\
\hline
\end{tabular}


Table 3 The preparation conditions of $\mathrm{CsPb}_{3}$

\begin{tabular}{|c|c|c|c|c|c|c|c|}
\hline Crystal morphology & Substrate & The ratio of precursor & $\begin{array}{c}\text { Protective gas/rate } \\
\text { of flow }\end{array}$ & $\begin{array}{c}T \\
\left({ }^{\circ} \mathrm{C}\right)\end{array}$ & $\begin{array}{c}P \\
\text { (Torr) }\end{array}$ & $\begin{array}{l}\text { Time } \\
(\mathrm{min})\end{array}$ & Ref. \\
\hline $\mathrm{CsPbCl}_{3}$ nanoplatelets & \multirow{5}{*}{ Muscovite mica } & $\mathrm{PbCl}_{2} / \mathrm{CsCl}=1: 1$ & \multirow{3}{*}{$\begin{array}{l}\text { High-purity } \\
\mathrm{N}_{2}(30 \mathrm{sccm})\end{array}$} & 625 & 100 & & {$[32]$} \\
\hline $\mathrm{CsPbBr}_{3}$ nanoplatelets & & $\mathrm{PbBr}_{2} / \mathrm{CsBr}=1: 1$ & & 575 & 50 & & {$[32]$} \\
\hline $\mathrm{CsPbI}_{3}$ nanoplatelets & & $\mathrm{PbI}_{2} / \mathrm{CsI}=1: 1$ & & 550 & 100 & 20 & {$[32]$} \\
\hline $\mathrm{CsPbCl}_{3} \mathrm{NWs}$ & & $\mathrm{PbCl}_{2} / \mathrm{CsCl}=1: 1$ & \multirow{2}{*}{ High-purity $\mathrm{N}_{2}$ gas } & 620 & 100 & & {$[75]$} \\
\hline $\mathrm{CsPbBr}{ }_{3} \mathrm{NWs}$ & & $\mathrm{PbBr}_{2} / \mathrm{CsBr}=1: 1$ & & 575 & 50 & & {$[75]$} \\
\hline $\mathrm{CsPbBr}{ }_{3} \mathrm{NWs}$ & & $\mathrm{PbBr}_{2} / \mathrm{CsBr}=1: 2$ & $\begin{array}{l}\text { High-purity } \\
\text { Ar (90 sccm) }\end{array}$ & 570 & 400 & 15 & {$[162]$} \\
\hline $\mathrm{CsPbBr}{ }_{3} \mathrm{MWs} / \mathrm{NWs}$ & $\mathrm{Si}$ & $\mathrm{PbBr}_{2} / \mathrm{CsBr}=1: 1$ & $\begin{array}{l}\text { High-purity } \\
\mathrm{N}_{2}(30 \mathrm{sccm})\end{array}$ & 575 & 100 & 10 & {$[74]$} \\
\hline $\mathrm{CsPbBr}{ }_{3}$ microspheres & & $\mathrm{PbBr}_{2} / \mathrm{CsBr}=1: 2$ & High-purity Ar gas & 575 & - & - & {$[157]$} \\
\hline
\end{tabular}

escence yields, and high light-absorption regions, contribute to their good application prospects in the field of lasers, photodetectors, X-ray detectors, $\gamma$-ray detectors, solar cells, p-light emitting diodes (LEDs), and so on. The quality of the metal halide is the key to the application of metal halide perovskites, and the growth technology has a significant impact on the material quality. Therefore, the research progress of several main methods for growing perovskite materials in recent years include the STL, ITC, AVC, spin-coating, and CVD methods. The STL, ITC, and AVC methods are usually used to grow large-sized bulk single crystals of perovskite. Although the STL method is more time-consuming, it can grow highquality large-scale bulk single crystals. The ITC method not only depends on the temperature of the solution but also requires stronger solvents. For example, DMF, DMSO, and GBA are the common solvents used in the ITC method. The solvents are generally different when the halogens vary in the perovskite single crystals. Singlecrystal perovskites can be grown rapidly by the AVC method, but the proper anti-solvent should be selected. In the AVC method, dichloromethane, toluene, ether, and ethanol are commonly used as anti-solvents. The spincoating method is mainly used to prepare high-performance polycrystalline or microcrystalline perovskite films for solar cells. However, the spin-coating method has some limitations in the preparation of large-area perovskite films. The CVD method can be used to grow large-area perovskite films by changing the growth device through the modification of the growth conditions; thus, perovskites with different morphologies, such as thin film, micro/nano platelet, NWs, and micro/nano sphere, can be prepared via the CVD method.

Although the methods of crystal growth are classified, two or three methods are often used together for growing high-quality single crystals. For example, the reported modified ITC method to grow $\mathrm{FAPbI}_{3}$ single crystals by Yang's group [56] included the STL and the ITC methods. Additionally, the reported HCVD method by Qi's group [99] included the spin-coating and the CVD methods. Therefore, to grow high-quality perovskite materials, the exploration of growth processes needs to continue. In addition, the toxicity of lead in perovskites has limited their commercial developments and applications. Therefore, it is more practical to study the growth and the associated methods of lead-free perovskites in the future. However, currently, it is difficult to commercialize the growth of perovskites. In the future, it will be necessary to explore low-cost, environmentally friendly, and convenient preparation methods of perovskite materials, which are also the necessitated conditions for the commercialization of perovskite materials.

\section{Received 6 January 2020; accepted 14 March 2020;}

published online 3 June 2020

1 Liu Y, Yang Z, Liu SF. Recent progress in single-crystalline perovskite research including crystal preparation, property evaluation, and applications. Adv Sci, 2018, 5: 1700471

2 Møller CK. Crystal structure and photoconductivity of cæsium plumbohalides. Nature, 1958, 182: 1436

3 Haque MA, Sheikh AD, Guan X, et al. Metal oxides as efficient charge transporters in perovskite solar cells. Adv Energy Mater, 2017, 7: 1602803

4 Liu Z, Mi Y, Guan X, et al. Morphology-tailored halide perovskite platelets and wires: from synthesis, properties to optoelectronic devices. Adv Opt Mater, 2018, 6: 1800413

5 Weber $\mathrm{D}$. $\mathrm{CH}_{3} \mathrm{NH}_{3} \mathrm{PbX}$, ein $\mathrm{Pb}$ (II)-system mit kubischer perowskitstruktur/ $\mathrm{CH}_{3} \mathrm{NH}_{3} \mathrm{PbX}_{3}$, a $\mathrm{Pb}$ (II)-system with cubic perovskite structure. Z für Naturforschung B, 1978, 33: 1443-1445

6 Weber D. $\mathrm{CH}_{3} \mathrm{NH}_{3} \mathrm{SnBr}_{x} \mathrm{I}_{3-x}(x=0-3)$, ein $\mathrm{Sn}(\mathrm{II})$-system mit kubischer perowskitstruktur/ $\mathrm{CH}_{3} \mathrm{NH}_{3} \mathrm{SnBr}_{x} \mathrm{I}_{3-x}(x=0-3)$, a $\mathrm{Sn}(\mathrm{II})-$ system with cubic perovskite structure. Z für Naturforschung B, 1978, 33: 862-865 
7 Kojima A, Teshima K, Shirai Y, et al. Organometal halide perovskites as visible-light sensitizers for photovoltaic cells. J Am Chem Soc, 2009, 131: 6050-6051

8 Dong R, Fang Y, Chae J, et al. High-gain and low-driving-voltage photodetectors based on organolead triiodide perovskites. Adv Mater, 2015, 27: 1912-1918

9 Zhang X, Sun C, Zhang Y, et al. Bright perovskite nanocrystal films for efficient light-emitting devices. J Phys Chem Lett, 2016, 7: 4602-4610

10 Stranks SD, Eperon GE, Grancini G, et al. Electron-hole diffusion lengths exceeding 1 micrometer in an organometal trihalide perovskite absorber. Science, 2013, 342: 341-344

11 Wehrenfennig C, Eperon GE, Johnston MB, et al. High charge carrier mobilities and lifetimes in organolead trihalide perovskites. Adv Mater, 2014, 26: 1584-1589

12 Jeon NJ, Noh JH, Yang WS, et al. Compositional engineering of perovskite materials for high-performance solar cells. Nature, 2015, 517: 476-480

13 Park NG. Perovskite solar cells: an emerging photovoltaic technology. Mater Today, 2015, 18: 65-72

14 Liu Y, Yang Z, Cui D, et al. Two-inch-sized perovskite $\mathrm{CH}_{3} \mathrm{NH}_{3} \mathrm{PbX}_{3}(\mathrm{X}=\mathrm{Cl}, \mathrm{Br}, \mathrm{I})$ crystals: growth and characterization. Adv Mater, 2015, 27: 5176-5183

15 Liu D, Wang Q, Traverse CJ, et al. Impact of ultrathin $\mathrm{C}_{60}$ on perovskite photovoltaic devices. ACS Nano, 2018, 12: 876-883

16 Sutherland BR, Sargent EH. Perovskite photonic sources. Nat Photon, 2016, 10: 295-302

17 Zhang Y, Liu Y, Li Y, et al. Perovskite $\mathrm{CH}_{3} \mathrm{NH}_{3} \mathrm{~Pb}\left(\mathrm{Br}_{x} \mathrm{I}_{1-x}\right)_{3}$ single crystals with controlled composition for fine-tuned bandgap towards optimized optoelectronic applications. J Mater Chem C, 2016, 4: 9172-9178

18 Murali B, Saidaminov MI, Abdelhady AL, et al. Robust and airstable sandwiched organo-lead halide perovskites for photodetector applications. J Mater Chem C, 2016, 4: 2545-2552

19 Li Y, Shi Z, Lei L, et al. Highly stable perovskite photodetector based on vapor-processed micrometer-scale $\mathrm{CsPbBr}_{3}$ microplatelets. Chem Mater, 2018, 30: 6744-6755

20 Tiep NH, Ku Z, Fan HJ. Recent advances in improving the stability of perovskite solar cells. Adv Energy Mater, 2016, 6: 1501420

21 Liang J, Wang C, Wang Y, et al. All-inorganic perovskite solar cells. J Am Chem Soc, 2016, 138: 15829-15832

22 Chen Q, Zhou H, Fang Y, et al. The optoelectronic role of chlorine in $\mathrm{CH}_{3} \mathrm{NH}_{3} \mathrm{PbI}_{3}(\mathrm{Cl})$-based perovskite solar cells. Nat Commun, 2015, 6: 7269

23 Jiang Q, Zhang L, Wang $\mathrm{H}$, et al. Enhanced electron extraction using $\mathrm{SnO}_{2}$ for high-efficiency planar-structure $\mathrm{HC}\left(\mathrm{NH}_{2}\right)_{2} \mathrm{PbI}_{3}$ based perovskite solar cells. Nat Energy, 2017, 2: 16177

24 Gao F, Zhao Y, Zhang X, et al. Recent progresses on defect passivation toward efficient perovskite solar cells. Adv Energy Mater, 2020, 10: 1902650

25 Wang $\mathrm{P}$, Zhang X, Zhou Y, et al. Solvent-controlled growth of inorganic perovskite films in dry environment for efficient and stable solar cells. Nat Commun, 2018, 9: 2225

26 Zhou H, Chen Q, Li G, et al. Interface engineering of highly efficient perovskite solar cells. Science, 2014, 345: 542-546

27 You J, Hong Z, Yang YM, et al. Low-temperature solutionprocessed perovskite solar cells with high efficiency and flexibility. ACS Nano, 2014, 8: 1674-1680

28 Guo Y, Yin X, Liu J, et al. Highly efficient $\mathrm{CsPbIBr}_{2}$ perovskite solar cells with efficiency over $9.8 \%$ fabricated using a preheatingassisted spin-coating method. J Mater Chem A, 2019, 7: 1900819016

29 Li M, Wei Q, Muduli SK, et al. Enhanced exciton and photon confinement in ruddlesden-popper perovskite microplatelets for highly stable low-threshold polarized lasing. Adv Mater, 2018, 30: 1707235

30 Zhou H, Yuan S, Wang X, et al. Vapor growth and tunable lasing of band gap engineered cesium lead halide perovskite micro/ nanorods with triangular cross section. ACS Nano, 2016, 11: 1189-1195

31 Zhang Q, Ha ST, Liu X, et al. Room-temperature near-infrared high-q perovskite whispering-gallery planar nanolasers. Nano Lett, 2014, 14: 5995-6001

32 Zhang Q, Su R, Liu X, et al. High-quality whispering-gallerymode lasing from cesium lead halide perovskite nanoplatelets. Adv Funct Mater, 2016, 26: 6238-6245

33 Chen J, Du W, Shi J, et al. Perovskite quantum dot lasers. InfoMat, 2020, 2: 170-183

34 Ling Y, Tian Y, Wang X, et al. Enhanced optical and electrical properties of polymer-assisted all-inorganic perovskites for lightemitting diodes. Adv Mater, 2016, 28: 8983-8989

35 Yantara N, Bhaumik S, Yan F, et al. Inorganic halide perovskites for efficient light-emitting diodes. J Phys Chem Lett, 2015, 6: 4360-4364

36 Li G, Rivarola FWR, Davis NJLK, et al. Highly efficient perovskite nanocrystal light-emitting diodes enabled by a universal crosslinking method. Adv Mater, 2016, 28: 3528-3534

37 Jin X, Zhang X, Fang H, et al. Facile assembly of high-quality organic-inorganic hybrid perovskite quantum dot thin films for bright light-emitting diodes. Adv Funct Mater, 2018, 28: 1705189

38 Wei Q, Li M, Zhang Z, et al. Efficient recycling of trapped energies for dual-emission in mn-doped perovskite nanocrystals. Nano Energy, 2018, 51: 704-710

39 Cao Y, Wang N, Tian H, et al. Perovskite light-emitting diodes based on spontaneously formed submicrometre-scale structures. Nature, 2018, 562: 249-253

40 Wang J, Wang N, Jin Y, et al. Interfacial control toward efficient and low-voltage perovskite light-emitting diodes. Adv Mater, 2015, 27: 2311-2316

41 Wang N, Cheng L, Ge R, et al. Perovskite light-emitting diodes based on solution-processed self-organized multiple quantum wells. Nat Photon, 2016, 10: 699-704

42 Lai ML, Tay TYS, Sadhanala A, et al. Tunable near-infrared luminescence in tin halide perovskite devices. J Phys Chem Lett, 2016, 7: 2653-2658

43 Swarnkar A, Chulliyil R, Ravi VK, et al. Colloidal $\mathrm{CsPbBr}_{3}$ perovskite nanocrystals: luminescence beyond traditional quantum dots. Angew Chem Int Ed, 2015, 54: 15424-15428

44 Pan $\mathrm{W}, \mathrm{Wu} \mathrm{H}$, Luo J, et al. $\mathrm{Cs}_{2} \mathrm{AgBiBr}_{6}$ single-crystal X-ray detectors with a low detection limit. Nat Photon, 2017, 11: 726-732

45 Saidaminov MI, Haque MA, Savoie M, et al. Perovskite photodetectors operating in both narrowband and broadband regimes. Adv Mater, 2016, 28: 8144-8149

46 Sun Z, Aigouy L, Chen Z. Plasmonic-enhanced perovskitegraphene hybrid photodetectors. Nanoscale, 2016, 8: 7377-7383

47 Lu J, Sheng X, Tong G, et al. Ultrafast solar-blind ultraviolet detection by inorganic perovskite $\mathrm{CsPbX}_{3}$ quantum dots radial junction architecture. Adv Mater, 2017, 29: 1700400

48 Tong G, Geng X, Yu Y, et al. Rapid, stable and self-powered 
perovskite detectors via a fast chemical vapor deposition process. RSC Adv, 2017, 7: 18224-18230

49 Li Y, Shi Z, Lei L, et al. Controllable vapor-phase growth of inorganic perovskite microwire networks for high-efficiency and temperature-stable photodetectors. ACS Photonics, 2018, 5: 2524-2532

50 Ding J, Fang H, Lian Z, et al. A self-powered photodetector based on a $\mathrm{CH}_{3} \mathrm{NH}_{3} \mathrm{PbI}_{3}$ single crystal with asymmetric electrodes. CrystEngComm, 2016, 18: 4405-4411

51 Gao L, Zeng K, Guo J, et al. Passivated single-crystalline $\mathrm{CH}_{3} \mathrm{NH}_{3} \mathrm{PbI}_{3}$ nanowire photodetector with high detectivity and polarization sensitivity. Nano Lett, 2016, 16: 7446-7454

52 Deng H, Dong D, Qiao K, et al. Growth, patterning and alignment of organolead iodide perovskite nanowires for optoelectronic devices. Nanoscale, 2015, 7: 4163-4170

53 Li J, Yuan S, Tang G, et al. High-performance, self-powered photodetectors based on perovskite and graphene. ACS Appl Mater Interfaces, 2017, 9: 42779-42787

54 Liu Y, Zhang Y, Yang Z, et al. Thinness- and shape-controlled growth for ultrathin single-crystalline perovskite wafers for mass production of superior photoelectronic devices. Adv Mater, 2016, 28: 9204-9209

55 Liu Y, Sun J, Yang Z, et al. 20-mm-large single-crystalline formamidinium-perovskite wafer for mass production of integrated photodetectors. Adv Opt Mater, 2016, 4: 1829-1837

56 Deng H, Yang X, Dong D, et al. Flexible and semitransparent organolead triiodide perovskite network photodetector arrays with high stability. Nano Lett, 2015, 15: 7963-7969

57 Chen Q, Wu J, Ou X, et al. All-inorganic perovskite nanocrystal scintillators. Nature, 2018, 561: 88-93

58 Luo Q, Ma H, Zhang Y, et al. Cross-stacked superaligned carbon nanotube electrodes for efficient hole conductor-free perovskite solar cells. J Mater Chem A, 2016, 4: 5569-5577

59 Liu T, Wang C, Hou J, et al. Enhanced electron collection in perovskite solar cells employing thermoelectric $\mathrm{NaCo}_{2} \mathrm{O}_{4} / \mathrm{TiO}_{2}$ coaxial nanofibers. Small, 2016, 12: 5146-5152

60 Luo Q, Zhang Y, Liu C, et al. Iodide-reduced graphene oxide with dopant-free spiro-ometad for ambient stable and high-efficiency perovskite solar cells. J Mater Chem A, 2015, 3: 15996-16004

61 Chen Q, Zhou H, Hong Z, et al. Planar heterojunction perovskite solar cells via vapor-assisted solution process. J Am Chem Soc, 2013, 136: 622-625

62 Liu M, Johnston MB, Snaith HJ. Efficient planar heterojunction perovskite solar cells by vapour deposition. Nature, 2013, 501: 395-398

63 Burschka J, Pellet N, Moon SJ, et al. Sequential deposition as a route to high-performance perovskite-sensitized solar cells. Nature, 2013, 499: 316-319

64 Dang Y, Liu Y, Sun Y, et al. Bulk crystal growth of hybrid perovskite material $\mathrm{CH}_{3} \mathrm{NH}_{3} \mathrm{PbI}_{3}$. CrystEngComm, 2015, 17: 665670

65 Lian Z, Yan Q, Gao T, et al. Perovskite $\mathrm{CH}_{3} \mathrm{NH}_{3} \mathrm{PbI}_{3}(\mathrm{Cl})$ single crystals: rapid solution growth, unparalleled crystalline quality, and low trap density toward $10^{8} \mathrm{~cm}^{-3}$. J Am Chem Soc, 2016, 138: 9409-9412

66 Ling Y, Tan L, Wang X, et al. Composite perovskites of cesium lead bromide for optimized photoluminescence. J Phys Chem Lett, 2017, 8: 3266-3271

67 Rakita Y, Kedem N, Gupta S, et al. Low-temperature solutiongrown $\mathrm{CsPbBr}_{3}$ single crystals and their characterization. Cryst
Growth Des, 2016, 16: 5717-5725

68 Saidaminov MI, Haque MA, Almutlaq J, et al. Inorganic lead halide perovskite single crystals: phase-selective low-temperature growth, carrier transport properties, and self-powered photodetection. Adv Opt Mater, 2017, 5: 1600704

69 Cho H, Jeong SH, Park MH, et al. Overcoming the electroluminescence efficiency limitations of perovskite light-emitting diodes. Science, 2015, 350: 1222-1225

70 Li C, Han C, Zhang Y, et al. Enhanced photoresponse of selfpowered perovskite photodetector based on $\mathrm{ZnO}$ nanoparticles decorated $\mathrm{CsPbBr}_{3}$ films. Sol Energy Mater Sol Cells, 2017, 172: 341-346

71 Liu X, Tan X, Liu Z, et al. Boosting the efficiency of carbon-based planar $\mathrm{Cs} \mathrm{PbBr}_{3}$ perovskite solar cells by a modified multistep spin-coating technique and interface engineering. Nano Energy, 2019, 56: 184-195

72 Wang Q, Zheng X, Deng Y, et al. Stabilizing the a-phase of $\mathrm{CsPbI}_{3}$ perovskite by sulfobetaine zwitterions in one-step spincoating films. Joule, 2017, 1: 371-382

73 Zhang $\mathrm{Q}, \mathrm{Zhu} \mathrm{W}$, Chen $\mathrm{D}$, et al. Light processing enables efficient carbon-based, all-inorganic planar $\mathrm{CsPbIBr}_{2}$ solar cells with high photovoltages. ACS Appl Mater Interfaces, 2019, 11: 2997-3005

74 Du W, Zhang S, Shi J, et al. Strong exciton-photon coupling and lasing behavior in all-inorganic $\mathrm{Cs} \mathrm{PbBr}_{3}$ micro/nanowire FabryPérot cavity. ACS Photonics, 2018, 5: 2051-2059

75 Gao Y, Zhao L, Shang Q, et al. Ultrathin $\mathrm{CsPbX}_{3}$ nanowire arrays with strong emission anisotropy. Adv Mater, 2018, 30: 1801805

76 Liu Z, Li Y, Guan X, et al. One-step vapor-phase synthesis and quantum-confined exciton in single-crystal platelets of hybrid halide perovskites. J Phys Chem Lett, 2019, 10: 2363-2371

77 Niu L, Zeng Q, Shi J, et al. Controlled growth and reliable thickness-dependent properties of organic-inorganic perovskite platelet crystal. Adv Funct Mater, 2016, 26: 5263-5270

$78 \mathrm{Ng} \mathrm{A}$, Ren Z, Shen Q, et al. Crystal engineering for low defect density and high efficiency hybrid chemical vapor deposition grown perovskite solar cells. ACS Appl Mater Interfaces, 2016, 8: 32805-32814

79 Ding J, Yan Q. Progress in organic-inorganic hybrid halide perovskite single crystal: growth techniques and applications. Sci China Mater, 2017, 60: 1063-1078

80 Wang Y, Chang S, Chen X, et al. Rapid growth of halide perovskite single crystals: from methods to optimization control. Chin J Chem, 2019, 37: 616-629

81 Fu Y, Rea MT, Chen J, et al. Selective stabilization and photophysical properties of metastable perovskite polymorphs of $\mathrm{CsPbI}_{3}$ in thin films. Chem Mater, 2017, 29: 8385-8394

82 Zeng J, Zhou H, Liu R, et al. Combination of solution-phase process and halide exchange for all-inorganic, highly stable $\mathrm{CsPbBr}$ perovskite nanowire photodetector. Sci China Mater, 2019, 62: 65-73

83 Chen J, Fu Y, Samad L, et al. Vapor-phase epitaxial growth of aligned nanowire networks of cesium lead halide perovskites $\left(\mathrm{CsPbX}_{3}, \mathrm{X}=\mathrm{Cl}, \mathrm{Br}, \mathrm{I}\right)$. Nano Lett, 2016, 17: 460-466

84 Chen J, Morrow DJ, Fu Y, et al. Single-crystal thin films of cesium lead bromide perovskite epitaxially grown on metal oxide perovskite $\left(\mathrm{SrTiO}_{3}\right)$. J Am Chem Soc, 2017, 139: 13525-13532

85 Mi Y, Liu Z, Shang Q, et al. Fabry-Pérot oscillation and room temperature lasing in perovskite cube-corner pyramid cavities. Small, 2018, 14: 1703136

86 Zhang Y, Liu Y, Yang Z, et al. High-quality perovskite $\mathrm{MAPbI}_{3}$ 
single crystals for broad-spectrum and rapid response integrate photodetector. J Energy Chem, 2018, 27: 722-727

87 Liu X, Liu Y, Gao F, et al. Photoinduced surface voltage mapping study for large perovskite single crystals. Appl Phys Lett, 2016, 108: 181604

88 Dang Y, Ju D, Wang L, et al. Recent progress in the synthesis of hybrid halide perovskite single crystals. CrystEngComm, 2016, 18: $4476-4484$

89 Li S, Zhang C, Song JJ, et al. Metal halide perovskite single crystals: from growth process to application. Crystals, 2018, 8: 220

90 Babu R, Giribabu L, Singh SP. Recent advances in halide-based perovskite crystals and their optoelectronic applications. Cryst Growth Des, 2018, 18: 2645-2664

91 Saidaminov MI, Abdelhady AL, Murali B, et al. High-quality bulk hybrid perovskite single crystals within minutes by inverse temperature crystallization. Nat Commun, 2015, 6: 7586

92 Eperon GE, Burlakov VM, Docampo P, et al. Morphological control for high performance, solution-processed planar heterojunction perovskite solar cells. Adv Funct Mater, 2014, 24: 151157

93 Im JH, Jang IH, Pellet $\mathrm{N}$, et al. Growth of $\mathrm{CH}_{3} \mathrm{NH}_{3} \mathrm{PbI}_{3}$ cuboids with controlled size for high-efficiency perovskite solar cells. Nat Nanotech, 2014, 9: 927-932

94 Tavakoli MM, Gu L, Gao Y, et al. Fabrication of efficient planar perovskite solar cells using a one-step chemical vapor deposition method. Sci Rep, 2015, 5: 14083

95 Wang B, Chen T. Exceptionally stable $\mathrm{CH}_{3} \mathrm{NH}_{3} \mathrm{PbI}_{3}$ films in moderate humid environmental condition. Adv Sci, 2016, 3: 1500262

96 Peng Y, Jing G, Cui T. A hybrid physical-chemical deposition process at ultra-low temperatures for high-performance perovskite solar cells. J Mater Chem A, 2015, 3: 12436-12442

97 Luo P, Liu Z, Xia W, et al. Chlorine-conducted defect repairment and seed crystal-mediated vapor growth process for controllable preparation of efficient and stable perovskite solar cells. J Mater Chem A, 2015, 3: 22949-22959

98 Luo P, Liu Z, Xia W, et al. A simple in situ tubular chemical vapor deposition processing of large-scale efficient perovskite solar cells and the research on their novel roll-over phenomenon in $J-V$ curves. J Mater Chem A, 2015, 3: 12443-12451

99 Leyden MR, Ono LK, Raga SR, et al. High performance perovskite solar cells by hybrid chemical vapor deposition. J Mater Chem A, 2014, 2: 18742-18745

100 Leyden MR, Lee MV, Raga SR, et al. Large formamidinium lead trihalide perovskite solar cells using chemical vapor deposition with high reproducibility and tunable chlorine concentrations. J Mater Chem A, 2015, 3: 16097-16103

101 Luo P, Liu Z, Xia W, et al. Uniform, stable, and efficient planarheterojunction perovskite solar cells by facile low-pressure chemical vapor deposition under fully open-air conditions. ACS Appl Mater Interfaces, 2015, 7: 2708-2714

102 Leyden MR, Jiang Y, Qi Y. Chemical vapor deposition grown formamidinium perovskite solar modules with high steady state power and thermal stability. J Mater Chem A, 2016, 4: 1312513132

103 Dong Q, Fang Y, Shao Y, et al. Electron-hole diffusion lengths $>175 \mu \mathrm{m}$ in solution-grown $\mathrm{CH}_{3} \mathrm{NH}_{3} \mathrm{PbI}_{3}$ single crystals. Science, 2015, 347: 967-970

104 Zhang H, Liu X, Dong J, et al. Centimeter-sized inorganic lead halide perovskite $\mathrm{CsPBBr}_{3}$ crystals grown by an improved solu- tion method. Cryst Growth Des, 2017, 17: 6426-6431

105 Saidaminov MI, Abdelhady AL, Maculan G, et al. Retrograde solubility of formamidinium and methylammonium lead halide perovskites enabling rapid single crystal growth. Chem Commun, 2015, 51: 17658-17661

106 Shi D, Adinolfi V, Comin R, et al. Low trap-state density and long carrier diffusion in organolead trihalide perovskite single crystals. Science, 2015, 347: 519-522

107 Mitzi DB, Feild CA, Schlesinger Z, et al. Transport, optical, and magnetic properties of the conducting halide perovskite $\mathrm{CH}_{3} \mathrm{NH}_{3} \mathrm{SnI}_{3}$. J Solid State Chem, 1995, 114: 159-163

108 Lian Z, Yan Q, Lv Q, et al. High-performance planar-type photodetector on (100) facet of $\mathrm{MAPbI}_{3}$ single crystal. Sci Rep, 2015, 5: 16563

109 Chae J, Dong Q, Huang J, et al. Chloride incorporation process in $\mathrm{CH}_{3} \mathrm{NH}_{3} \mathrm{PbI}_{3-x} \mathrm{Cl}_{x}$ perovskites via nanoscale bandgap maps. Nano Lett, 2015, 15: 8114-8121

$110 \mathrm{Su}$ J, Chen DP, Lin CT. Growth of large $\mathrm{CH}_{3} \mathrm{NH}_{3} \mathrm{PbX}$ (X=I, Br) single crystals in solution. J Cryst Growth, 2015, 422: 75-79

$111 \mathrm{Xu} \mathrm{Z}, \mathrm{Li} \mathrm{H}$, Zhao $\mathrm{H}$, et al. Optimizing optoelectronic performances by controlling halide compositions of $\operatorname{MAPb}\left(\mathrm{Cl}_{x} \mathrm{I}_{1-x}\right)_{3}$ single crystals. CrystEngComm, 2019, 21: 4169-4174

112 Dang Y, Zhong C, Zhang G, et al. Crystallographic investigations into properties of acentric hybrid perovskite single crystals $\mathrm{NH}\left(\mathrm{CH}_{3}\right)_{3} \mathrm{SnX}_{3}(\mathrm{X}=\mathrm{Cl}, \mathrm{Br})$. Chem Mater, 2016, 28: 6968-6974

113 Han Q, Bae SH, Sun P, et al. Single crystal formamidinium lead iodide $\left(\mathrm{FAPbI}_{3}\right)$ : insight into the structural, optical, and electrical properties. Adv Mater, 2016, 28: 2253-2258

114 Huang Y, Li L, Liu Z, et al. The intrinsic properties of $\mathrm{FA}_{(1-x)} \mathrm{MA}_{x} \mathrm{PbI}_{3}$ perovskite single crystals. J Mater Chem A, 2017, 5: 8537-8544

115 Dang Y, Zhou Y, Liu X, et al. Formation of hybrid perovskite tin iodide single crystals by top-seeded solution growth. Angew Chem Int Ed, 2016, 55: 3447-3450

116 Dirin DN, Cherniukh I, Yakunin S, et al. Solution-grown $\mathrm{CsPbBr}_{3}$ perovskite single crystals for photon detection. Chem Mater, 2016, 28: 8470-8474

117 Liu Y, Ren X, Zhang J, et al. $120 \mathrm{~mm}$ single-crystalline perovskite and wafers: towards viable applications. Sci China Chem, 2017, 60: 1367-1376

118 Yang $\mathrm{Y}$, Yan $\mathrm{Y}$, Yang M, et al. Low surface recombination velocity in solution-grown $\mathrm{CH}_{3} \mathrm{NH}_{3} \mathrm{PbBr}_{3}$ perovskite single crystal. Nat Commun, 2015, 6: 7961

119 Fang HH, Adjokatse S, Wei $\mathrm{H}$, et al. Ultrahigh sensitivity of methylammonium lead tribromide perovskite single crystals to environmental gases. Sci Adv, 2016, 2: e1600534

120 Liao Q, Hu K, Zhang H, et al. Perovskite microdisk microlasers self-assembled from solution. Adv Mater, 2015, 27: 3405-3410

121 Chen $\mathrm{F}, \mathrm{Xu} \mathrm{C}, \mathrm{Xu} \mathrm{Q}$, et al. Structure evolution of $\mathrm{CH}_{3} \mathrm{NH}_{3} \mathrm{PbBr}_{3}$ single crystal grown in $\mathrm{N}, \mathrm{N}$-dimethylformamide solution. Cryst Growth Des, 2018, 18: 3132-3137

122 Zhou H, Nie Z, Yin J, et al. Antisolvent diffusion-induced growth, equilibrium behaviours in aqueous solution and optical properties of $\mathrm{CH}_{3} \mathrm{NH}_{3} \mathrm{PbI}_{3}$ single crystals for photovoltaic applications. RSC Adv, 2015, 5: 85344-85349

123 Grancini G, D'Innocenzo V, Dohner ER, et al. $\mathrm{CH}_{3} \mathrm{NH}_{3} \mathrm{PbI}_{3}$ perovskite single crystals: surface photophysics and their interaction with the environment. Chem Sci, 2015, 6: 7305-7310

124 Wehrenfennig C, Liu M, Snaith HJ, et al. Charge-carrier dynamics in vapour-deposited films of the organolead halide per- 
ovskite $\mathrm{CH}_{3} \mathrm{NH}_{3} \mathrm{PbI}_{3-x} \mathrm{Cl}_{x}$. Energy Environ Sci, 2014, 7: 22692275

125 Tidhar Y, Edri E, Weissman H, et al. Crystallization of methyl ammonium lead halide perovskites: implications for photovoltaic applications. J Am Chem Soc, 2014, 136: 13249-13256

126 Saidaminov MI, Adinolfi V, Comin R, et al. Planar-integrated single-crystalline perovskite photodetectors. Nat Commun, 2015, 6: 8724

127 Ding J, Du S, Zuo Z, et al. High detectivity and rapid response in perovskite $\mathrm{CsPbBr}_{3}$ single-crystal photodetector. J Phys Chem C, 2017, 121: 4917-4923

128 Dursun I, De Bastiani M, Turedi B, et al. $\mathrm{CsPb}_{2} \mathrm{Br}_{5}$ single crystals: synthesis and characterization. ChemSusChem, 2017, 10: 37463749

129 Peng W, Wang L, Murali B, et al. Solution-grown monocrystalline hybrid perovskite films for hole-transporter-free solar cells. Adv Mater, 2016, 28: 3383-3390

130 Yang Z, Xu Q, Wang X, et al. Large and ultrastable all-inorganic $\mathrm{CsPbBr}_{3}$ monocrystalline films: low-temperature growth and application for high-performance photodetectors. Adv Mater, 2018, 30: 1802110

131 Yang Z, Lu J, ZhuGe M, et al. Controllable growth of aligned monocrystalline $\mathrm{CsPbBr}_{3}$ microwire arrays for piezoelectric-induced dynamic modulation of single-mode lasing. Adv Mater, 2019, 31: 1900647

132 Pascoe AR, Gu Q, Rothmann MU, et al. Directing nucleation and growth kinetics in solution-processed hybrid perovskite thinfilms. Sci China Mater, 2017, 60: 617-628

133 Zhou Y, Game OS, Pang S, et al. Microstructures of organometal trihalide perovskites for solar cells: their evolution from solutions and characterization. J Phys Chem Lett, 2015, 6: 4827-4839

134 LaMer VK, Dinegar RH. Theory, production and mechanism of formation of monodispersed hydrosols. J Am Chem Soc, 1950, 72: 4847-4854

135 Cao G, Wang Y. Nanostructures and Nanomaterials: Synthesis, Properties and Applications. 2nd Edition. London: Imperial College Press, 2004

136 Huang F, Li M, Siffalovic P, et al. From scalable solution fabrication of perovskite films towards commercialization of solar cells. Energy Environ Sci, 2019, 12: 518-549

137 Lu J, Chen SC, Zheng Q. Defect passivation of $\mathrm{CsPbIBr}_{2}$ perovskites for high-performance solar cells with large open-circuit voltage of 1.28 V. ACS Appl Energy Mater, 2018, 1: 5872-5878

138 Liang J, Zhao $\mathrm{P}$, Wang $\mathrm{C}$, et al. $\mathrm{CsPb}_{0.9} \mathrm{Sn}_{0.1} \mathrm{IBr}_{2}$ based allinorganic perovskite solar cells with exceptional efficiency and stability. J Am Chem Soc, 2017, 139: 14009-14012

139 Gao LL, Liang LS, Song XX, et al. Preparation of flexible perovskite solar cells by a gas pump drying method on a plastic substrate. J Mater Chem A, 2016, 4: 3704-3710

140 Li X, Bi D, Yi C, et al. A vacuum flash-assisted solution process for high-efficiency large-area perovskite solar cells. Science, 2016, 353: $58-62$

$141 \mathrm{Xu} \mathrm{Y,} \mathrm{Zhu} \mathrm{L,} \mathrm{Shi} \mathrm{J,} \mathrm{et} \mathrm{al.} \mathrm{Efficient} \mathrm{hybrid} \mathrm{mesoscopic} \mathrm{solar} \mathrm{cells}$ with morphology-controlled $\mathrm{CH}_{3} \mathrm{NH}_{3} \mathrm{PbI}_{3-x} \mathrm{Cl}_{x}$ derived from twostep spin coating method. ACS Appl Mater Interfaces, 2015, 7: 2242-2248

142 Yang WS, Park BW, Jung EH, et al. Iodide management in formamidinium-lead-halide-based perovskite layers for efficient solar cells. Science, 2017, 356: 1376-1379

$143 \mathrm{Kim} \mathrm{YH}$, Cho H, Heo JH, et al. Multicolored organic/inorganic hybrid perovskite light-emitting diodes. Adv Mater, 2015, 27: $1248-1254$

144 Tan ZK, Moghaddam RS, Lai ML, et al. Bright light-emitting diodes based on organometal halide perovskite. Nat Nanotech, 2014, 9: 687-692

145 Longo G, Pertegás A, Martínez-Sarti L, et al. Highly luminescent perovskite-aluminum oxide composites. J Mater Chem C, 2015, 3: 11286-11289

146 Chen B, Bai Y, Yu Z, et al. Efficient semitransparent perovskite solar cells for $23.0 \%$-efficiency perovskite/silicon four-terminal tandem cells. Adv Energy Mater, 2016, 6: 1601128

147 Wang N, Cheng L, Si J, et al. Morphology control of perovskite light-emitting diodes by using amino acid self-assembled monolayers. Appl Phys Lett, 2016, 108: 141102

148 Zhang $\mathrm{X}$, Wang $\mathrm{W}, \mathrm{Xu} \mathrm{B}$, et al. Thin film perovskite light-emitting diode based on $\mathrm{CsPbBr}_{3}$ powders and interfacial engineering. Nano Energy, 2017, 37: 40-45

149 Zhu W, Zhang Q, Chen D, et al. Intermolecular exchange boosts efficiency of air-stable, carbon-based all-inorganic planar $\mathrm{CsPbIBr}_{2}$ perovskite solar cells to over 9\%. Adv Energy Mater, 2018, 8: 1802080

150 Rao H, Ye S, Gu F, et al. Morphology controlling of all-inorganic perovskite at low temperature for efficient rigid and flexible solar cells. Adv Energy Mater, 2018, 8: 1800758

151 Jeon NJ, Noh JH, Kim YC, et al. Solvent engineering for highperformance inorganic-organic hybrid perovskite solar cells. Nat Mater, 2014, 13: 897-903

152 Lou YH, Li M, Wang ZK. Seed-mediated superior organometal halide films by $\mathrm{GeO}_{2}$ nano-particles for high performance perovskite solar cells. Appl Phys Lett, 2016, 108: 053301

153 Xiao Z, Bi C, Shao Y, et al. Efficient, high yield perovskite photovoltaic devices grown by interdiffusion of solution-processed precursor stacking layers. Energy Environ Sci, 2014, 7: 2619-2623

154 Hwang K, Jung YS, Heo YJ, et al. Toward large scale roll-to-roll production of fully printed perovskite solar cells. Adv Mater, 2015, 27: 1241-1247

155 Mitzi DB, Prikas MT, Chondroudis K. Thin film deposition of organic-inorganic hybrid materials using a single source thermal ablation technique. Chem Mater, 1999, 11: 542-544

156 Huo C, Liu X, Song X, et al. Field-effect transistors based on vander-Waals-grown and dry-transferred all-inorganic perovskite ultrathin platelets. J Phys Chem Lett, 2017, 8: 4785-4792

157 Du W, Zhang S, Wu Z, et al. Unveiling lasing mechanism in $\mathrm{CsPbBr}_{3}$ microsphere cavities. Nanoscale, 2019, 11: 3145-3153

158 Wang Y, Sun X, Chen Z, et al. High-temperature ionic epitaxy of halide perovskite thin film and the hidden carrier dynamics. Adv Mater, 2017, 29: 1702643

159 Leyden MR, Meng L, Jiang Y, et al. Methylammonium lead bromide perovskite light-emitting diodes by chemical vapor deposition. J Phys Chem Lett, 2017, 8: 3193-3198

160 Sanders S, Stümmler D, Pfeiffer P, et al. Chemical vapor deposition of organic-inorganic bismuth-based perovskite films for solar cell application. Sci Rep, 2019, 9: 9774

161 Li G, Che T, Ji X, et al. Record-low-threshold lasers based on atomically smooth triangular nanoplatelet perovskite. Adv Funct Mater, 2019, 29: 1805553

$162 \mathrm{Wu} \mathrm{Z}$, Chen J, Mi Y, et al. All-inorganic $\mathrm{CsPbBr}_{3}$ nanowire based plasmonic lasers. Adv Opt Mater, 2018, 6: 1800674

163 Liu X, Niu L, Wu C, et al. Periodic organic-inorganic halide perovskite microplatelet arrays on silicon substrates for room- 
temperature lasing. Adv Sci, 2016, 3: 1600137

164 Xing J, Liu XF, Zhang Q, et al. Vapor phase synthesis of organometal halide perovskite nanowires for tunable room-temperature nanolasers. Nano Lett, 2015, 15: 4571-4577

Acknowledgements This work was supported by the Ministry of Science and Technology (2016YFA0200700 and 2017YFA0205004), the National Natural Science Foundation of China (21673054, 11874130, 61307120, 61704038 and 11474187) and the Open Research Fund Program of the State Key Laboratory of Low-Dimensional Quantum Physics (KF201902).

Author contributions Wang S mainly drafted the manuscript, while Yang F, Cao Q, Zhong Y, Wang A, and Du W assisted Wang S to complete the literature research, draw up the tables, and discuss the ideas of the article. Liu X led the project.

Conflict of interest The authors declare that they have no conflict of interests.

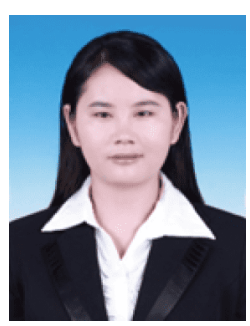

Shaoli Wang received her MSc degree from Beijing University of Technology in 2011, and $\mathrm{PhD}$ degree from the Institute of Chemistry, Chinese Academy of Sciences in 2014. Then she joined the Experiment Center of Forestry in North China, Chinese Academy of Forestry and engaged in material-related scientific research. At the end of August 2019, she joined the research group of Xinfeng Liu at the National Center for Nanoscience and Technology (NCNST) to study the new nano materials.

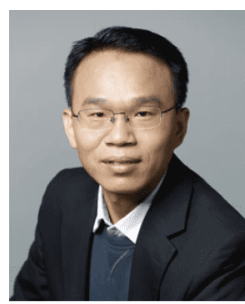

Xinfeng Liu is a professor at the NCNST, China. $\mathrm{He}$ received his $\mathrm{PhD}$ in 2011 at NCNST. Then he joined the School of Physical and Mathematical Sciences of Nanyang Technological University, Singapore, as a postdoctoral fellow. He joined the "100-Talents" Program of the Chinese Academy of Sciences in 2015 and became a professor of NCNST since then. His research group mainly focuses on light-matter interaction and ultrafast spectroscopy at micro-to-nanometer scale.

\section{金属卤化物钙钛矿材料生长方法研究进展}

王少丽 ${ }^{1,2}$, 杨凡 ${ }^{2,3}$, 朱江瑞, 操沁璇, ${ }^{2,4}$ 钟阳光 ${ }^{2}$, 王傲成 ${ }^{2,3}$, 杜文娜党, 刘新风 ${ }^{2,5^{*}}$

摘要 钙钛矿材料尤其是金属卤化物钙钛矿具有优异的性能, 如较 大的光系数、较高的载流子迁移率、较长的载流子寿命、可调谐 的电阻率、较大的X射线衰减系数和简单的处理工艺等. 这些优点 使得钻钛矿材料在光电领域, 如太阳能电池、发光二极管、光电 探测器、 $\mathrm{X} / \gamma$ 射线探测器和激光等研究领域引起了广泛关注. 钻钛 矿材料的广泛应用依赖于高质量的钻钛矿晶体或薄膜. 截至目前, 已经涌现出众多的钻铁矿生长技术和方法. 本综述分类总结了近 年来用于钙钛矿材料生长的主要方法和手段, 包括溶液降温法、 逆温结晶法、反溶剂法、旋涂法和化学气相沉积法等. 通过总结 与分析, 发现溶液降温法、逆温结晶法、反溶剂法主要用于生长 高质量的钙钛矿单晶, 旋涂法在制备钙钛矿薄膜方面具有较大优 势, 而化学气相沉积法则在制备多种形貌的微纳钻钠矿材料方面 占据优势. 本综述可为科研人员在钲钛矿材料生长方面提供可参 考的依据和具体参数. 